\title{
Assessing the spatial and temporal variability of greenhouse gas emissions from different configurations of on-site wastewater treatment system using discrete and continuous gas flux measurement
}

\author{
Jan Knappe, Celia Somlai, and Laurence W. Gill \\ Department of Civil, Structural and Environmental Engineering, Trinity College Dublin, \\ The University of Dublin, Dublin, Ireland
}

Correspondence: Laurence W. Gill (laurence.gill@tcd.ie)

Received: 27 July 2021 - Discussion started: 9 September 2021

Revised: 20 December 2021 - Accepted: 13 January 2022 - Published: 18 February 2022

\begin{abstract}
Global emissions linked to wastewater treatment are estimated to account for up to $1.5 \%$ of total greenhouse gas (GHG) emissions globally. However, few studies have measured GHG emissions from domestic on-site treatment systems (DWWTSs) directly. In this study, two DWWTSs were monitored for $446 \mathrm{~d}$ and $>42000$ gas flux measurements were conducted using both discrete spot measurements and continuous flux chamber deployments. The observed GHG fluxes from biological activity in the soil and water phase were found to be highly spatially and temporally variable and correlated to environmental factors, water usage patterns and system design. In total, the results show that a septic tank discharging effluent into a well-designed soil treatment unit is estimated to emit a net $9.99 \mathrm{~kg}-\mathrm{CO}_{2}$ eq. $\mathrm{cap}^{-1} \mathrm{yr}^{-1}$, with approximately $63 \%, 27 \%$ and $10 \%$ of the total $\mathrm{CO}_{2}$-equivalent net emissions in the form of $\mathrm{CO}_{2}, \mathrm{CH}_{4}$ and $\mathrm{N}_{2} \mathrm{O}$, respectively. Emissions from the septic tank surface contributed over $50 \%$ of total emissions and tended to be strongly underestimated by one-off discrete measurements, especially when episodic ebullitive events are to be considered. Fluxes from the soil treatment unit (STU) stemmed from both the soil surface and the vent system. Soil fluxes were mostly influenced by temperature but peaked regularly under conditions of rapidly changing soil water content. Vent fluxes were mostly governed by effluent, quality and a low number of high-emission events were responsible for the majority of total observed vent emissions. Owing to the strong overall spatial and temporal heterogeneity of observed fluxes from DWWTSs across all
\end{abstract}

modules, future studies should focus on continuous deployments of a number of flux chambers over discrete measurements to accurately assess GHG emissions from on-site systems. This study also provided insights into managing GHG emissions from DWWTSs by different system configuration design, as well as indicating that the current IPCC emission factors for $\mathrm{CH}_{4}$ and $\mathrm{N}_{2} \mathrm{O}$ significantly overestimate emissions for on-site wastewater treatment systems.

\section{Introduction}

Overall greenhouse gas (GHG) emissions from the waste and wastewater sector contribute an estimated $2 \%$ to the total national emissions in Ireland (EPA, 2018). Global emissions linked to wastewater treatment are estimated to account for up to $1.5 \%$ of total $\mathrm{GHG}$ and $5 \%$ of non- $\mathrm{CO}_{2}$ GHG emissions and are expected to contribute $42 \%$ to all waste-related GHG emissions by 2030, compared to $36 \%$ in 1990 (Bogner et al., 2008; US EPA, 2012). The quantification of direct GHG emissions from wastewater treatment systems is currently based on the application of estimation methodologies that have been published by the Intergovernmental Panel on Climate Change (IPCC, 2013). However, national and global estimations are considered highly uncertain as they are based on a limited number of case studies and rely heavily on secondary assumptions such as load-based calculations or emission factors rather than primary data. 
Most research on GHG emissions from wastewater to date has been carried out on centralised, large-scale treatment systems (Cakir and Stenstrom, 2005; Czepiel et al., 1993; Johansson et al., 2004; Yver Kwok et al., 2015; Masuda et al., 2015; Yoshida et al., 2014). Few studies, however, have directly measured GHG emissions from decentralised and/or on-site wastewater treatment systems (Diaz-Valbuena et al., 2011; Huynh et al.,, 2021; Leverenz et al., 2011; SomlaiHaase et al., 2017; Somlai et al., 2019; Truhlar et al., 2016; Wigginton et al., 2020), despite an estimated $20 \%$ of the population relying on on-site wastewater treatment in the European Economic Area and the United States (EEA, 2013; US EPA, 2016). The proportion of these systems is significantly higher in low- and middle-income countries in comparison to the global average, reckoned to provide improved sanitation for up to $64 \%$ of such countries' populations (Blackett et al., 2014).

Domestic on-site wastewater treatment systems (DWWTSs) are environmentally and economically sustainable, small scale, decentralised systems usually comprising a septic tank (ST) for collection, storage and partial treatment of effluent, sometimes followed by a manufactured secondary treatment unit, which then discharges into some form of soil treatment unit (STU) (Cooper et al., 2016; Gill et al., 2009). DWWTSs are suitable for off-the-grid solutions as they fundamentally rely on naturally occurring biogeochemical processes for the treatment of wastewater. Despite their apparently straightforward design, the biogeochemical processes involved are complex and involve a wide range of microbial populations existing in different redox conditions (Beal et al., 2005; Tomaras et al., 2009). Two main redox environments are usually defined for on-site systems (Wilhelm et al., 1994): the first zone in the ST is an anaerobic environment where high concentrations of organic $\mathrm{C}$ are mainly degraded via hydrolysis acidogenesis, and methanogenesis producing $\mathrm{CO}_{2}$ and $\mathrm{CH}_{4}$; the second redox zone is the STU in which both aerobic and anaerobic conditions usually exist. The oxygen required for aerobic oxidation of organic $\mathrm{C}$ in the partially treated effluent (and consequent production of $\mathrm{CO}_{2}$ ) is supplied by gaseous diffusion within the unsaturated zone.

In STU trenches, a biomat forms at the infiltrative surface with time and gradually clogs soil pores. The development of this biomat layer is linked to the physical accumulation of suspended solids within soil pores and microbial growth (McKinley and Siegrist, 2010; Thomas et al., 1966; Beach et al., 2005; Siegrist and Boyle, 1987; Knappe et al., 2020; Jones and Taylor, 1965; Bouma, 1975). As gradual biomat development results in a growing resistance to flow and reductions in hydraulic conductivity, ponding of effluent at the trench base can occur, and anaerobic conditions may develop (Beach et al., 2005; Hu et al., 2007; Knappe et al., 2020; Siegrist and Boyle, 1987; Van Cuyk et al., 2001). Within these ponded infiltration trenches and mature biomats, as well as other areas of the STU which lack oxygen such as sat- urated microsites, anaerobic organisms (e.g. methanogenic bacteria) act to break down insoluble organic compounds into $\mathrm{CO}_{2}$ and $\mathrm{CH}_{4}$. Furthermore, it has been suggested that elevated concentrations of $\mathrm{CH}_{4}$ in the soil above the infiltration trenches can host a population of methanotrophs, which may function to reduce overall $\mathrm{CH}_{4}$ fluxes from the STU to the atmosphere (Fernández-Baca et al., 2018).

In this study two operational DWWTSs were instrumented and monitored for more than a year in order to provide the first quantification of total net GHG emissions (including $\mathrm{CO}_{2}, \mathrm{CH}_{4}$ and $\mathrm{N}_{2} \mathrm{O}$ measurements from the septic tank, the STU and the vent system). The STUs at both DWWTSs received effluent of two different strengths (primary treated effluent high in organics and $\mathrm{NH}_{4}-\mathrm{N}$ as well as secondary treated effluent with lower organic strength but high in $\mathrm{NO}_{3}-\mathrm{N}$ ), enabling the impact of pre-treatment on GHG emissions from the soil to be directly compared.

\section{Study design and methods}

\subsection{Research sites}

Two new DWWTSs were constructed as research sites serving single detached houses in Co. Limerick, Ireland. Site A, a pumped-flow system, was constructed in 2015, and Site B, a gravity-flow-based system, was constructed in 2016. Both sites were instrumented with inserts for gas flux measurements within the four-trench STU and undisturbed control soil, a weather station and a network of soil sensors for monitoring volumetric water content (VWC). Both systems consisted of a two-chamber prefabricated concrete septic tank (Aswasep Septic Tank NS4S, Molloy Precast, Ireland), each with a capacity of $4760 \mathrm{~L}$. Following the ST, one half (two trenches) of the STU was directly fed with primary effluent (PE) from the ST, while the other half (two further trenches) of the STU was fed with secondary treated effluent (SE) that underwent additional treatment by a media filter (coconut husk) or rotating biological contactor (RBC) at Sites A and $\mathrm{B}$, respectively. The $\mathrm{RBC}$ is a fixed-film, secondary wastewater treatment process in which plastic discs slowly rotate and bring the attached biofilm down into the sewage (the substrate) and then up into the air (for oxygen transfer). Splitting the effluent between primary and secondary treated effluent-fed trenches allowed for the direct comparison of GHG emissions from STUs receiving effluent of different pre-treatment levels under identical subsoil, meteorological and environmental conditions. The research sites, soil characteristics and water quality data over a 2-year intensive monitoring period were reported in detail in Knappe et al. (2020) A short characterisation of the research sites is given in Table 1. 
Table 1. Overview of site characteristics and installed system as reported in Knappe et al. (2020).

\begin{tabular}{lll}
\hline Parameter & Site A & Site B \\
\hline Location & Kilmallock, Co. Limerick & Crecora, Co. Limerick \\
Subsoil type & Sandy loam & Loam \\
Sand - silt - clay & $59 \%-30 \%-11 \%$ & $49 \%-34 \%-17 \%$ \\
Bulk density & $1.44 \mathrm{~g} \mathrm{~cm}^{3}$ & $1.20 \mathrm{~g} \mathrm{~cm}^{3}$ \\
Porosity & 0.386 & 0.448 \\
Saturated hydraulic conductivity & $30.9 \mathrm{cmd}^{-1}$ & $13.9 \mathrm{~cm} \mathrm{~d}^{-1}$ \\
Construction & September 2015 & April 2016 \\
Primary treatment & Septic tank & Septic tank \\
Secondary treatment & Cocopeat media filter & Rotating biological contactor \\
Flow regime & Pumped flow & Gravity flow \\
Number of occupants & 5 & 4 \\
\hline
\end{tabular}

\subsection{GHG flux measurements}

\subsubsection{Equipment and flux calculation}

An integrated and automated soil gas flux measurement systems for $\mathrm{CO}_{2}$ (LI-8100A, Li-Cor Biosciences, Inc.) and $\mathrm{CH}_{4}$ (UGGA 915-0011, Los Gatos Research) was employed to measure concentrations from gas flux chamber inserts, the vent system and dissolved gases in the effluent. A detailed description of the measuring system used in this research was published in Somlai-Haase et al. (2017). Due to temporary instrument failure of the $\mathrm{CH}_{4}$ analyser, more measurements are available in general for $\mathrm{CO}_{2}$ compared to $\mathrm{CH}_{4}$ fluxes. Additional gas samples were collected manually from the sampling loop through a tee fitting with a septum (8100-664 Trace Gas Sample Kit, Li-Cor Biosciences, Inc.) for analysis of $\mathrm{CH}_{4}$ and $\mathrm{N}_{2} \mathrm{O}$ by gas chromatography in the laboratory at Trinity College Dublin. For that, $50 \mathrm{~mL}$ of gas was extracted from the gas loop and transferred into sealed, preevacuated $20 \mathrm{~mL}$ vials for transport. Samples were, then, injected and analysed within $72 \mathrm{~h}$ using a gas chromatograph (Clarus 500, Perkin Elmer) equipped with capillary columns (Elite-Plot Q), a flame ionisation detector for $\mathrm{CH}_{4}$ and an electron capture detector for $\mathrm{N}_{2} \mathrm{O}$.

Fluxes were calculated using a mass balance approach as described in Somlai-Haase et al. (2017) and also in the Supplement. Observations resulting in model fits with low overall $R^{2}$ values $\left(R^{2}<0.9\right.$ for $\mathrm{CO}_{2}$ and $R^{2}<0.8$ for $\mathrm{CH}_{4}$ and $\mathrm{N}_{2} \mathrm{O}$ ) were assumed compromised and discarded, representing a total of $1 \%, 21 \%$ and $3 \%$ of $\mathrm{CO}_{2}, \mathrm{CH}_{4}$ and $\mathrm{N}_{2} \mathrm{O}$ measurements, respectively. Flux values were, then, scaled and converted into a mass flux of gas per capita (expressed in $\mathrm{gcap}^{-1} \mathrm{~d}^{-1}$ ) using the ideal gas law and household occupancy levels.

\subsubsection{Fluxes from the septic tank}

Gas fluxes from the ST were evaluated using discrete and continuous measurements. Discrete spot survey measure- ments were carried out during each site visit $(n=14$ and 13 for $\mathrm{CO}_{2}$ for Sites A and B, respectively; $n=9$ and 8 for $\mathrm{CH}_{4}$ for Sites A and B, respectively) by placing the survey chamber (LI-8100 103, Li-Cor Biosciences, Inc.) on fixed inserts standing on submerged tripods in each of the two ST chambers for a period of $5 \mathrm{~min}$ at a time (see Supplement for details). Further continuous measurements $(>18 \mathrm{~h})$ were carried out over the secondary ST chamber once per site using the automated survey chamber mounted on the same fixed insert in order to assess the diurnal variability of observed fluxes (Site A: 24/25 July 2018; Site B: 20/21 November 2017). To quantify dissolved concentrations in the effluent, grab samples $(100 \mathrm{~mL})$ were collected from both ST chambers and transferred into a bubbler bottle and connected to the gas analyser (see Supplement for details). Effluent temperature, electrical conductivity (EC), $\mathrm{pH}$ and dissolved $\mathrm{O}_{2}$ were recorded simultaneously using a multiparameter kit (ProfiLine Multi 3320, WTW GmbH, Germany), and dissolved $\mathrm{CO}_{2}$ and $\mathrm{CH}_{4}$ concentrations were estimated using the headspace method (Hope et al., 1995).

\subsubsection{Fluxes from the STU}

A total of 20 inserts were permanently installed in the soil at random locations over the first $6 \mathrm{~m}$ of each STU area (Fig. 1). Some of these were located directly above the gravel-filled trenches (above which the original topsoil had been replaced after being excavated), with the other inserts located above undisturbed soil within the STU areas. A further four inserts were located over undisturbed soil away from the area of the STUs to act as the best available controls in both sites. All inserts were installed to a depth of approximately $5 \mathrm{~cm}$ with another $5 \mathrm{~cm}$ clearance above ground on which flux chambers could be placed. Both discrete and continuous measurements were used to quantify gas fluxes from the STU. Discrete spot measurements were carried out sequentially during each site visit $\left(n=13\right.$ and 15 for $\mathrm{CO}_{2}$ at Sites $\mathrm{A}$ and $\mathrm{B}$, respectively; $n=5$ and 8 for $\mathrm{CH}_{4}$ at Sites A and B, respectively) to quantify the spatial distribution of fluxes over the 


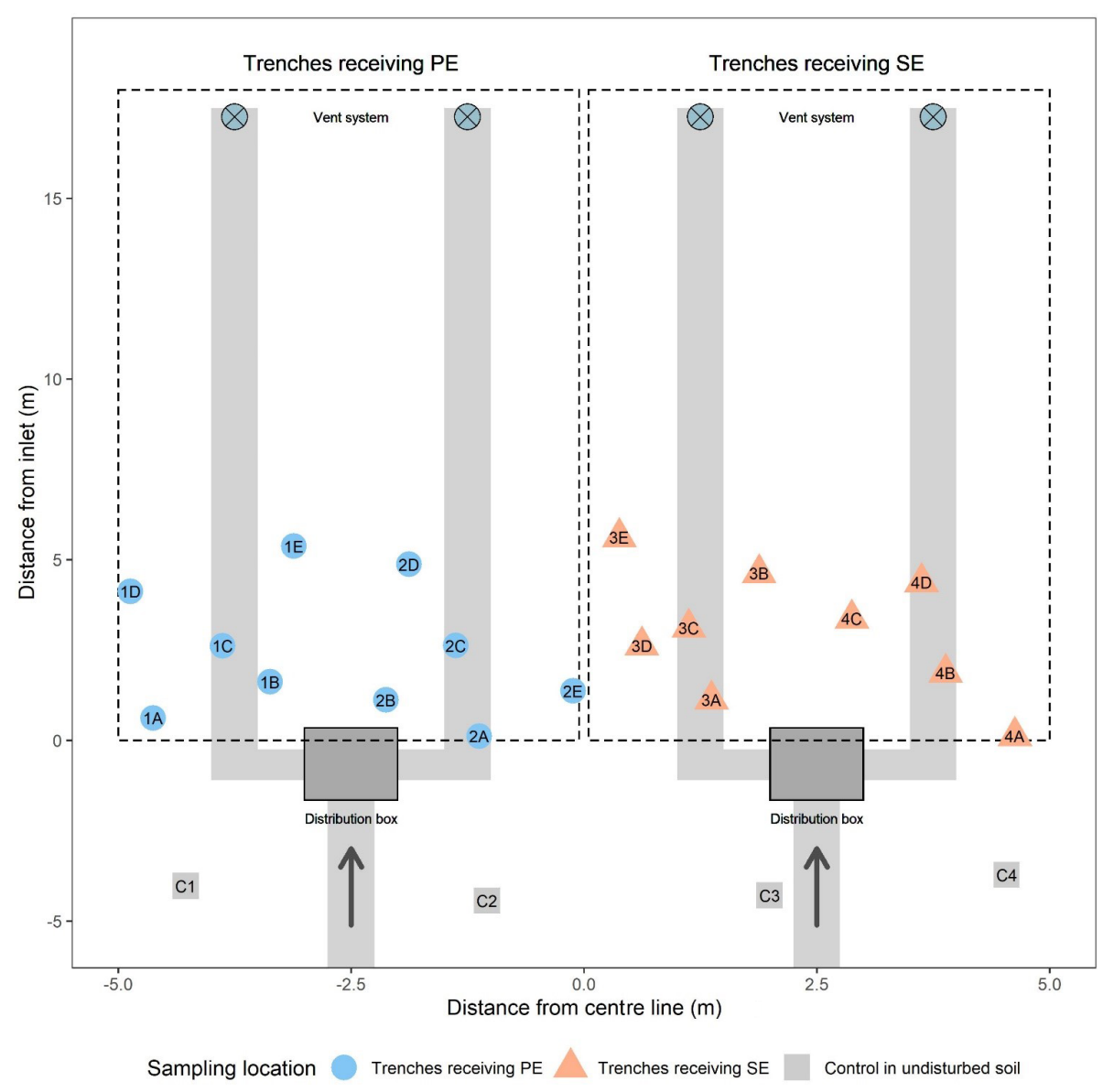

Figure 1. Positions of permanently installed inserts for gas flux measurements within the STU over trenches receiving primary effluent (PE; blue circles) and secondary effluent (SE; red pyramids) and in undisturbed soil (control; yellow squares) on both sites. The effluent inflow is marked by arrows. Subsurface trenches are marked in grey. Vents are marked by crosses on blue circles.

STU by placing the survey chamber for an incubation period of $3 \mathrm{~min}$ over each of the 24 inserts. In between site visits, continuous flux measurements were carried out over four randomly chosen soil inserts (one per trench) within the STU and one control. Measurements over each insert were automatically taken once an hour with a 6 min incubation period. The deployment of continuous measurements was alternated between both sites and left in place until the next site visit, resulting in continuous diurnal flux time series of between 14 and 37 consecutive days. Discrete $\mathrm{N}_{2} \mathrm{O}$ fluxes were only measured on eight occasions on each site, due to instrument availability and increased manual handling effort.

\subsubsection{Fluxes from the vent system}

Perforated effluent distribution pipes embedded in the STU gravel trenches were connected to above-surface vents by elbows fitted at the end of each pipe. Gases escaping through these vents were captured using a Vent Wizard 800+ (inhouse development; see Supplement) consisting of a sealed end cap with a single gas line connected to the gas sampling loop. Before capping, the average temperature and undisturbed air velocity inside the vent were determined using a hot-wire anemometer (LU8050, TQC Sheen, NL). Subsequently, gas concentrations inside the capped vent system were monitored for at least $3 \mathrm{~min}$ and until no further increase was observed. Gas fluxes from the vent were then determined by scaling the final steady-state gas concentration observed inside the vent with the surface area of the vent port and determined air flow velocity inside the vent $(n=9$ and 8 for $\mathrm{CO}_{2}$ for Sites A and B, respectively; $n=4$ and 3 for $\mathrm{CH}_{4}$ for Sites A and B, respectively). Additional samples for $\mathrm{N}_{2} \mathrm{O}$ were collected on six occasions from each site.

\subsection{Auxiliary data}

Meteorological data were recorded at both sites using a weather station (Campbell Scientific Ltd, UK). Mean air temperature, barometric pressure, net radiation, rainfall, relative humidity, wind direction and wind speed were used to calculate Penman-Monteith potential evapotranspiration (Allen et al., 1998; Shahidian et al., 2012) and soil moisture 
deficit (Schulte et al., 2005). A network of soil sensors (type EC5 and GS3, Decagon Devices, Inc., USA) installed within the STU and control soil provided detailed information on VWC content, soil temperature and pore water EC and were used to infer the development of a microbially active zone, i.e. biomat, along the base of STU trenches over time (see Knappe et al., 2020).

Throughout the study the pollutant and hydraulic loads in the systems were monitored and presented in detail in Knappe et al. (2020). The mean daily wastewater production for each household was 287 and $500 \mathrm{Ld}^{-1}$ at Sites A and B, respectively, of which approximately one-fourth was delivered into each of the four STU trenches. While the overall pollutant loading out of the ST at Site A was generally lower compared to Site B, the RBC installed at Site B performed considerably better when it came to removing organics and TN than the media filter at Site A.

Effluent distribution inside the STU trenches was traced using a network of soil sensors (type EC5 and GS3, Decagon Devices, Inc., USA) installed within the STU which provided detailed information on VWC, soil temperature and pore water EC. The relatively higher organic loading in trenches receiving $\mathrm{PE}$ at both sites caused the development of an extensive biomat, spreading approximately $15 \mathrm{~m}$ along the trenches after 3 years of operation. The biomat growth in the trenches receiving $\mathrm{SE}$ did not extend to more than 7.5 and $10 \mathrm{~m}$ at Site A and Site B, respectively, reflecting more limited biomat growth due to the lower availability of organics and nutrients in the effluent feeding these trenches (Knappe et al., 2020). The percolation of the effluent through the soil caused a significant reduction in organic $\mathrm{C}$ concentrations within the first $300 \mathrm{~mm}$ depth below the infiltrative surface (Dubber et al., 2021) and net $\mathrm{N}$ removal more effective in trenches receiving $\mathrm{PE}$ as also found in previous studies of STUs (e.g. Beal et al., 2005; Gill et al., 2009).

\subsection{Data collection and statistical analysis}

All on-site sensor data were collected hourly on a CR1000 data logger (Campbell Scientific Ltd, UK). Data analysis was carried out using R, version 3.6.2 (R Core Team, 2019). Statistical significance of between-treatment medians was calculated using Wilcoxon signed-rank tests and is reported using $p$ values or adjusted $p_{\text {adj }}$ values with Bonferroni correction (in the case of multiple comparisons). Substantive significance is reported as standardised effect sizes $\bar{r}$, a relative measure for the magnitude of the difference between groups (Sullivan and Feinn, 2012). The significance level $\alpha=0.05$ was used to test all hypotheses. Bias-corrected and accelerated bootstrap $95 \%$ confidence intervals were determined around the medians and effect sizes using 5000 resampling draws (Carpenter and Bithell, 2000; Banjanovic and Osborne, 2016). Confidence intervals are reported in brackets next to the point estimate. Where applicable, correlations are evaluated using Pearson's $r$ coefficient.

\section{Results and discussion}

\subsection{Total number of observations}

To assess the spatial and temporal variability of GHG emission from two DWWTSs, 42198 gas flux measurements over the course of 446 d in 2017-2018 were collected using discrete spot measurements and continuous deployments (Fig. S1 in the Supplement). A total of 781, 382 and 62 observations were measured as discrete spot measurements throughout the study period for $\mathrm{CO}_{2}, \mathrm{CH}_{4}$ and $\mathrm{N}_{2} \mathrm{O}$, respectively (Table 1), as well as 34660 and 6313 observations during continuous deployments of automated gas flux chambers for $\mathrm{CO}_{2}$ and $\mathrm{CH}_{4}$, respectively. The total number of $\mathrm{CH}_{4}$ measurements was lower than those for $\mathrm{CO}_{2}$ mainly due to limited instrument availability due to instrument breakdown. Approximately $2.5 \%$ of the observations were recorded at the ST surface, $0.5 \%$ at the STU vent system and the remainder over the STU from the soil gas flux measurements, mainly during the automated long-term deployments.

\subsection{Fluxes from the ST}

As the effluent passes through the anaerobic environment of the two-chamber ST, microbiological degradation of organic matter via hydrolysis, acidogenesis and methanogenesis produces $\mathrm{CO}_{2}$ and $\mathrm{CH}_{4}$. No significant production of $\mathrm{N}_{2} \mathrm{O}$ would be expected in the $\mathrm{ST}$ as there is almost no nitrate present in incoming raw sewage, and the prevailing environment would not support the prerequisite oxidation of organic $\mathrm{N}$ and ammonium. Fluxes were directly measured from the ST surface in both chambers using fixed collars and discrete measurements.

Discrete flux measurements inside the ST revealed that fluxes of $\mathrm{CO}_{2}$ from the first chamber were generally higher than fluxes from the second chamber (Fig. S2A in the Supplement). Median $\mathrm{CO}_{2}$ emissions from the first chamber $\left(\mathrm{Md}=3.50 \mu \mathrm{mol} \mathrm{CO} \mathrm{m}^{-2} \mathrm{~s}^{-1}\right)$ were generally higher compared to the second chamber $\left(\mathrm{Md}=2.63 \mu \mathrm{mol} \mathrm{CO} 2 \mathrm{~m}^{-2} \mathrm{~s}^{-1}\right)$ and expressed peak values of up to 18.52 and $7.85 \mu \mathrm{molCO} \mathrm{Cm}^{-2} \mathrm{~s}^{-1}$, respectively (Table $\mathrm{S} 2$ in the Supplement), which could be attributed to the fact that flow conditions within the first chamber are generally expected to be more turbulent due to pulses of incoming effluent during periods of peak flow. This difference was significant with moderate effect size $(p=0.016 ; \bar{r}=0.48$ $[0.13 ; 0.76])$ and was corroborated by (i) slightly higher dissolved $\mathrm{CO}_{2}$ concentrations found in effluent samples from the first chamber $\left(\mathrm{Md}=18.65 \mathrm{mg} \mathrm{CO}_{2} \mathrm{~L}^{-1}\right)$ compared to the second chamber $\left(\mathrm{Md}=12.98 \mathrm{mg} \mathrm{CO}_{2} \mathrm{~L}^{-1}\right)$ and (ii) a significant positive correlation between observed $\mathrm{CO}_{2}$ fluxes across both chambers with respective wastewater TOC concentration $(p<0.001 ; r=0.51)$. This indicates that the release of $\mathrm{CO}_{2}$ from the ST surface was mainly driven by the availabil- 
ity of organic matter as opposed to temperature, which was not correlated with $\mathrm{CO}_{2}$ fluxes $(p=0.29 ; \bar{r}=0.15)$.

On the contrary, measurements of discrete $\mathrm{CH}_{4}$ fluxes inside the ST revealed that fluxes were slightly higher in the second chamber compared to the first chamber (Fig. S2B in the Supplement). Median $\mathrm{CH}_{4}$ emissions were 0.21 and $0.34 \mu \mathrm{mol} \mathrm{CH} \mathrm{C}^{-2} \mathrm{~s}^{-1}$ in the first and second chambers, respectively. However, the first chamber expressed higher variability with peaks of up to 1.86 and $1.07 \mu \mathrm{molCH}_{4} \mathrm{~m}^{-2} \mathrm{~s}^{-1}$ (Table S1 in the Supplement), which again could be attributed to the fact the flow conditions within the first chamber are generally expected to be more erratic. The overall difference between both chambers was not significant, and the estimated effect size was small, albeit with a wide confidence interval $(p=0.76 ; \bar{r}=0.09[0.01 ; 0.65])$. Median dissolved $\mathrm{CH}_{4}$ concentrations followed this pattern and were 0.25 and $0.41 \mathrm{mgCH}_{4} \mathrm{~L}^{-1}$ in the first and second chambers, respectively. $\mathrm{CH}_{4}$ fluxes from the $\mathrm{ST}$ correlated with neither organic content $(p=0.92 ; \bar{r}=-0.02)$ nor temperature ( $p=0.16 ; \bar{r}=0.26)$, indicating that methane production becomes more prevalent as the microbiological degradation of organic matter progresses in the ST. Initial measurements of $\mathrm{N}_{2} \mathrm{O}$ did not yield detectable fluxes from either chamber and were thus discontinued after three occasions.

\section{Diurnal measurements}

To assess the representativeness of the one-off discrete measurements, continuous measurements of fluxes from the second chamber were performed on each site. At Site A, 280 flux measurements were taken within $24 \mathrm{~h}$ in July 2018. At Site B, 220 flux measurements were taken within $19.5 \mathrm{~h}$ in November 2017.

While Site A expressed high fluctuations of observed fluxes with a considerable number of ebullitive events for both $\mathrm{CO}_{2}\left(\mathrm{CV}\right.$ 0.49) and $\mathrm{CH}_{4}(\mathrm{CV}$ 0.68), fluxes at Site B expressed more gradual changes in observed fluxes over the course of the day without distinct ebullitive events for both $\mathrm{CO}_{2}$ (CV 0.13) and $\mathrm{CH}_{4}$ (CV 0.19) (Fig. 2a, Table S3 in the Supplement). Both sites expressed a distinct diurnal behaviour with $43.1 \%$ and $0.5 \%$ of observed values measured during the continuous chamber deployment falling outside the range of fluxes observed during the discrete chamber deployment at Sites A and B, respectively (Fig. 2a). The lack of distinct ebullitive events at Site B could be linked to the overall lower mean ambient temperatures during the trial in November for Site B $\left(12.5^{\circ} \mathrm{C}\right)$ compared to July for Site A $\left(18.1^{\circ} \mathrm{C}\right)$, as colder months are marked by overall lower microbial activity and higher gas solubility, thus lowering the potential for detecting gas fluxes from the surface. Additionally, the presence of a thick scum layer (approx. $30 \mathrm{~cm}$ ) that had accumulated within the first chamber of the ST at Site B effectively reduced overall turbulence caused by peak flow events. At Site A, however, periods of both high $\mathrm{CO}_{2}$ and $\mathrm{CH}_{4}$ fluxes were clearly correlated with water usage patterns and peaks occurring in the morning, around noon and again in the evening hours (Fig. 2a), indicating that the hydraulic disturbance in the ST must have led to degassing of dissolved gases and dislodgement of entrapped gas bubbles that had built up in the tank.

Comparing flux values obtained by continuous and discrete measurements shows that observed fluxes obtained by discrete measurements were significantly lower $(p<0.001$ for $\mathrm{CO}_{2}$ and $p=0.032$ for $\mathrm{CH}_{4}$ ), indicating that discrete measurements underestimated fluxes from the ST surface by a factor of up to 2 for median fluxes and up to 7 for peak fluxes (Fig. 2b). These results suggest that flux estimates derived from discrete measurements alone were generally not sufficient to capture the full range of fluxes occurring from a ST. Discrete measurements tended to underestimate median GHG fluxes by up to $2.75 \mu \mathrm{molCO} \mathrm{CO}^{-2} \mathrm{~s}^{-1}$ and $0.77 \mu \mathrm{molCH}_{4} \mathrm{~m}^{-2} \mathrm{~s}^{-1}$ at each site, especially when episodic ebullitive events are to be considered. This matches findings by researchers investigating methane emissions from freshwater streams, lakes and reservoirs (Bastviken et al., 2011; Natchimuthu, 2016).

The measurement of dissolved $\mathrm{CO}_{2}$ and $\mathrm{CH}_{4}$ concentrations in both chambers of the STs broadly reflected the gas fluxes: higher $\mathrm{CO}_{2}$ concentrations in chamber 1 than 2 , compared to higher $\mathrm{CH}_{4}$ concentrations in chamber 2 than 1 (Table S4 in the Supplement). The difference between $\mathrm{CO}_{2}$ and $\mathrm{CH}_{4}$ fluxes and dissolved concentrations across both chambers might be explained by the compartmentalisation of subsequent stages of low-rate anaerobic digestion in the ST: in the first stage, organic matter is converted to simple organic compounds and volatile fatty acids producing mostly $\mathrm{CO}_{2}$, and in the second stage, the soluble organic acids (which will have leached into the bulk liquid and passed into the second chamber) are stabilised by methanogens, and most of the $\mathrm{CH}_{4}$ is produced. A parallel study into sludge accumulation in the STs at these sites (Gill et al., 2018) showed that the first chambers of the STs had approximately 5 times higher sludge mass accumulation compared to the second chambers after 2 years of operation.

Studies measuring GHG emissions from 10 STs receiving only black water in Vietnam using a similar floating chamber method found significant emissions of both $\mathrm{CO}_{2}$ and $\mathrm{CH}_{4}$ (7.39 and $91.37 \mathrm{~kg} \mathrm{cap}^{-1} \mathrm{yr}^{-1}$, respectively) in the first chamber while $\mathrm{N}_{2} \mathrm{O}$ emissions were negligible (Huyn et al., 2021). Notably, STs that have not been de-sludged within the preceding 5 years of the study expressed significantly higher $\mathrm{CH}_{4}$ emissions compared to regularly desludged tanks. While the systems in our study were $<5$ years old at the time of sampling, it is not uncommon to observe de-sludging intervals of 5 years or higher in Ireland (Mac Mahon et al., 2022). For such tanks it is likely that $>40 \%$ of the tank volume is occupied by sludge, which means a denser sludge layer at the bottom with longer solids retention time, allowing enough time for the relatively slow growth of 
(a)
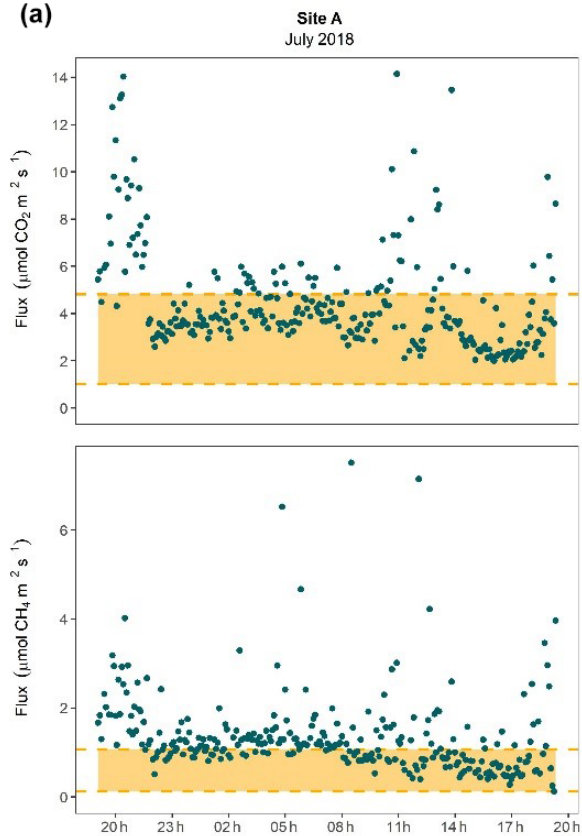
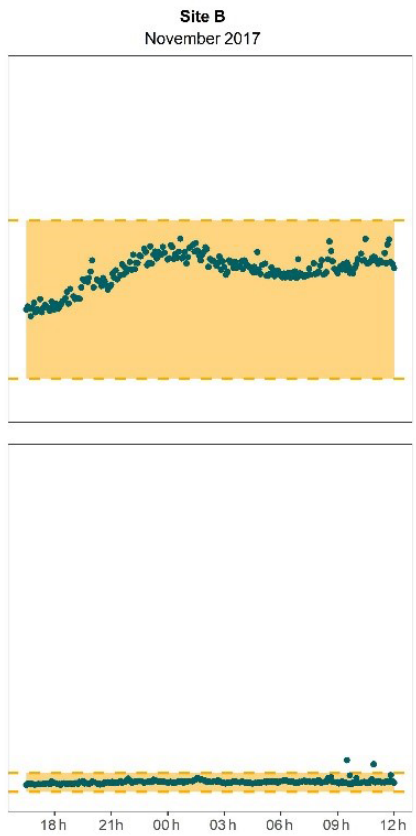

(b)
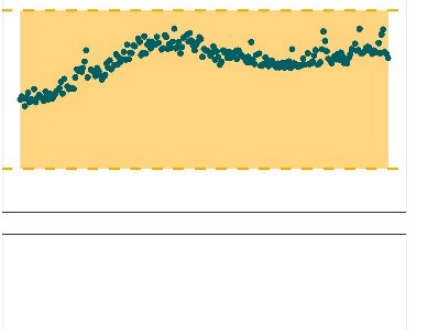

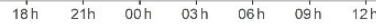
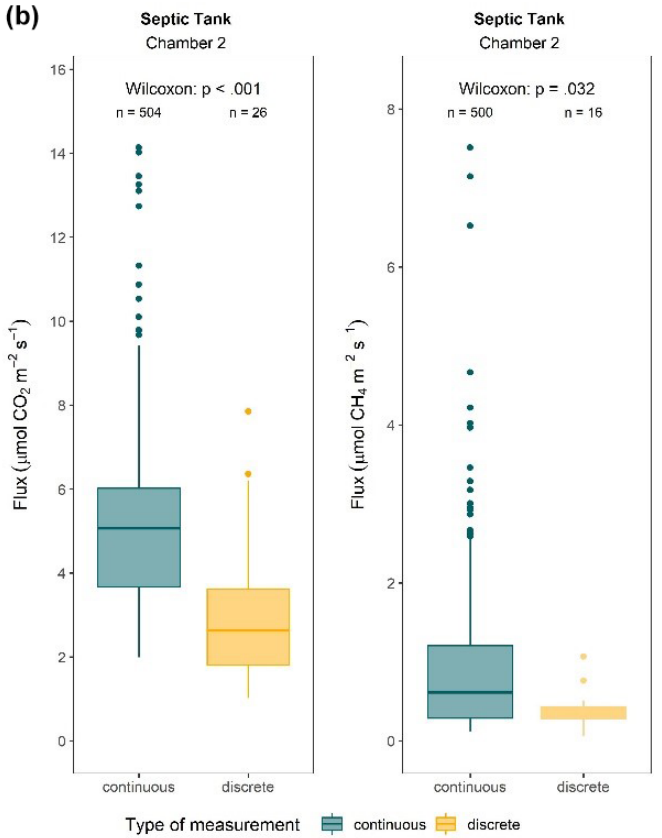

Figure 2. $\mathrm{CO}_{2}$ and $\mathrm{CH}_{4}$ fluxes from the ST. (a) Comparison of the time series of observed fluxes from the second chamber of STs at Sites A and B during overnight deployment (blue circles) with a range of fluxes observed during discrete measurements (red shaded area). Dashed lines represent respective minimum and maximum flux values as observed during discrete measurements, which were usually taken in the late morning or early afternoon. (b) Boxplots of observed fluxes for $\mathrm{CO}_{2}$ and $\mathrm{CH}_{4}$ over the ST second chamber measured with continuous and discrete chamber deployment. Statistical results are presented as the $p$ value of Wilcoxon signed rank tests with estimated effect size $r$ and corresponding boot-strapped $95 \%$ confidence intervals; $n$ denotes the number of observations per group.

methanotrophs and conditions to promote anaerobic digestion.

\subsection{Fluxes from the STU}

\subsubsection{Discrete measurements}

To assess the spatial variability of GHG fluxes from the STU, a total of 1017 discrete gas flux measurements were performed over 20 permanently installed inserts in the STU (plus four control inserts over undisturbed soil) of which approximately $65 \%$ were conducted for assessing $\mathrm{CO}_{2}, 30 \%$ for $\mathrm{CH}_{4}$ and the remainder for $\mathrm{N}_{2} \mathrm{O}$ fluxes. Measurements were taken on 13 and 15 sampling dates for Sites A and B, respectively, over a period of 15 consecutive months (Fig. S1). Discrete measurements were usually taken during late morning or early afternoon.

Discrete measurements revealed that fluxes of $\mathrm{CO}_{2}$ above the trenches in the STU receiving $\mathrm{PE}(\mathrm{Md}=3.00[2.70$; $\left.3.38] \mu \mathrm{molCO}_{2} \mathrm{~m}^{-2} \mathrm{~s}^{-1}\right)$ were slightly lower $\left(p_{\text {adj }}=0.33\right.$; $\underline{r}=0.07[0.00 ; 0.19])$ than those fluxes measured at the Control $\left(\mathrm{Md}=3.06[2.51 ; 3.62] \mu \mathrm{molCO}_{2} \mathrm{~m}^{-2} \mathrm{~s}^{-1}\right)$ but not significantly. Discrete measurements of $\mathrm{CO}_{2}$ above the trenches receiving $\mathrm{SE}\left(\mathrm{Md}=2.73[2.40 ; 3.04] \mu \mathrm{molCO}_{2} \mathrm{~m}^{-2} \mathrm{~s}^{-1}\right)$ were significantly lower than those above the Control $\left(p_{\text {adj }}=0.02 ; \underline{r}=0.18[0.05 ; 0.30]\right)$. The $\mathrm{CO}_{2}$ fluxes from above the PE trenches were significantly higher than the fluxes above SE trenches ( $p_{\text {adj }}=0.048 ; \underline{r}=0.15[0.02$; $0.28]$ ).

With respect to $\mathrm{CH}_{4}$, there were almost no detectable fluxes measured above the STU trenches receiving either PE $\left(\mathrm{Md}=0.002[-0.001 ; 0.004] \mathrm{nmolCH}_{4} \mathrm{~m}^{-2} \mathrm{~s}^{-1}\right)$ or SE $\left(\mathrm{Md}=-0.001[-0.003 ; 0.001] \mathrm{nmolCH}_{4} \mathrm{~m}^{-2} \mathrm{~s}^{-1}\right)$ with no significant difference between them $\left(p_{\text {adj }}=0.44\right.$; $\bar{r}=0.08[0.00 ; 0.26])$. Although the $\mathrm{CH}_{4}$ fluxes above both the trenches receiving $\mathrm{PE}$ and $\mathrm{SE}$ were significantly higher than the fluxes measured at the Control $\left(p_{\text {adj }}=0.02 ; \bar{r}=0.28[0.08 ; 0.46]\right.$ and $p_{\text {adj }}=0.002$; $\bar{r}=0.36[0.16 ; 0.52])$, it should be noted that $\mathrm{CH}_{4}$ fluxes from the control areas at both sites were negative or non-detectable throughout all discrete measurements $\left(\mathrm{Md}=-0.004[-0.008 ; 0.004] \mathrm{nmolCH}_{4} \mathrm{~m}^{-2} \mathrm{~s}^{-1}\right)$ and ranged from -3.36 to $0.01 \mathrm{nmolCH}_{4} \mathrm{~m}^{-2} \mathrm{~s}^{-1}$. Hence, the undisturbed control soils acted as a $\mathrm{CH}_{4}$ sink, which is in line with previous findings from soils of grasslands and unfertilised pastures, e.g. reported by Mosier et al. (1991, 1997), Dunfield et al. (1995) and Braun et al. (2013).

Discrete measurements of $\mathrm{N}_{2} \mathrm{O}$ fluxes above the trenches receiving $\mathrm{PE} \quad(\mathrm{Md}=-0.02 \quad[-0.06$; $\left.0.03] \mathrm{nmolN}_{2} \mathrm{Om}^{-2} \mathrm{~s}^{-1}\right)$ and $\mathrm{SE} \quad(\mathrm{Md}=0.05 \quad[0.01$ $0.09] \mathrm{nmolN}_{2} \mathrm{O} \mathrm{m}^{-2} \mathrm{~s}^{-1}$ ) were slightly lower than those fluxes measured at the Control $(\mathrm{Md}=0.06$ 
$\left.[-0.02 ; 0.08] \mathrm{nmolN}_{2} \mathrm{Om}^{-2} \mathrm{~s}^{-1}\right)$ but not significantly so $\left(p_{\text {adj }}=0.33 ; \underline{r}=0.32[0.01 ; 0.61]\right.$ and $p_{\text {adj }}=0.33$; $\underline{r}=0.26[0.01 ; 0.57]$, respectively). There was no significant difference between the $\mathrm{N}_{2} \mathrm{O}$ fluxes measured above the PE trenches compared to the SE trenches ( $p_{\text {adj }}=0.95 ; \underline{r}=0.01$ $[0.00 ; 0.03])$.

\subsubsection{Spatial distribution}

The spatial distribution of the net fluxes was analysed, first as a function of distance from the inlet pipes to the STU, as shown in Fig. 3a. A comparison of the regression lines, whilst each is not significantly different from zero, does show that $\mathrm{CO}_{2}$ fluxes above the section of the STU receiving PE seem to increase with distance, compared to only a very slight increase in emissions above the SE trenches with distance. In comparison, $\mathrm{CH}_{4}$ emissions above the $\mathrm{PE}$ trenches, whilst again not found to be statistically significant, decrease with distance compared to almost no change with distance above the SE side of the STU. Equally, no change with distance is revealed for the $\mathrm{N}_{2} \mathrm{O}$ fluxes above either the PE or SE side of the STU.

The spatial distribution of the net fluxes was then analysed with respect to the lateral position of where the emissions were measured, whether located directly over the percolation trenches or between the trenches in the STU, as shown in Fig. 3b. For the STU receiving PE, higher net $\mathrm{CO}_{2}$ fluxes were measured from positions located between trenches $\left(\mathrm{Md}=0.53[0.34 ; 0.84] \mu \mathrm{molCO}_{2} \mathrm{~m}^{-2} \mathrm{~s}^{-1}\right)$ compared to inserts located above trenches $(\mathrm{Md}=-0.32[-0.48$; $\left.-0.07] \mu \mathrm{molCO}_{2} \mathrm{~m}^{-2} \mathrm{~s}^{-1}\right)$. The same pattern was found for the SE side of the STUs, with higher net fluxes between trenches $\left(\mathrm{Md}=0.27[0.00 ; 0.42] \mu \mathrm{molCO} \mathrm{CO}^{-2} \mathrm{~s}^{-1}\right)$ compared to inserts located above trenches $(\mathrm{Md}=-0.71[-0.92$; $\left.-0.51] \mu \mathrm{mol} \mathrm{CO}_{2} \mathrm{~m}^{-2} \mathrm{~s}^{-1}\right)$. Both differences are significant $(p<0.001)$ and have a moderate effect size $(\bar{r}=0.26[0.26$; $38]$ and $\bar{r}=0.32$ [0.33; 43] for PE and SE trenches, respectively). This indicates that some $\mathrm{CO}_{2}$ being generated in and below the trenches must be making its way to the atmosphere back up through the gravel and the percolation pipes via the vents (and not up through the soil), as quantified and discussed later. For $\mathrm{CH}_{4}$ the median net fluxes over inserts located between or over gravel trenches for both trenches receiving PE and SE were both zero. However, the presence of a sufficient number of high-emission events combined with a near-complete lack of uptake events captured during discrete measurements rendered the flux observed directly over trenches $\left(\mathrm{Md}=0.01[0.00 ; 0.60] \mathrm{nmolCH}_{4} \mathrm{~m}^{-2} \mathrm{~s}^{-1}\right)$ significantly different $(p=0.008)$ from fluxes observed between trenches. For $\mathrm{N}_{2} \mathrm{O}$ there were generally very low net fluxes for between and directly over trenches. Due to the limited sample size, no statistical difference was detected. The very low net fluxes suggest that nitrogenous compounds in the effluent in the form of ammonia and organic nitrogen are being transformed via nitrification into soluble nitrate (which percolates down to the underlying groundwater) and/or complete dentification or anammox to generate $\mathrm{N}_{2}$ gas as the final product (Gill et al., 2009).

\subsubsection{Continuous measurements}

To assess the temporal variability of GHG fluxes from the STU, automated gas flux measurements were performed at hourly intervals over a set of four of the 20 permanently installed inserts in the STU (plus one of the four control inserts over undisturbed soil). Measurements were taken over the course of a total of 154 and $195 \mathrm{~d}$ for Sites A and B, respectively.

During the continuous deployment of gas flux chambers, the undisturbed control soil emitted a median flux of $5.10 \mu \mathrm{molCO} \mathrm{CO}_{2}^{-2} \mathrm{~s}^{-1}$, which was significantly more $\left(p_{\text {adj }}=0.001\right)$ than the STU for trenches receiving $\mathrm{PE} \quad\left(\mathrm{Md}=2.17 \mu \mathrm{molCO}_{2} \mathrm{~m}^{-2} \mathrm{~s}^{-1}\right)$ and $\mathrm{SE}$ $\left(\mathrm{Md}=2.05 \mu \mathrm{molCO} \mathrm{m}^{-2} \mathrm{~s}^{-1}\right)-$ see Table S5 in the Supplement. This finding, which matches the pattern from the discrete measurements, suggests that either the architecture of the STUs must be providing an alternative pathway for the gases being generated by the microbial breakdown of the organics in the effluent (as well as gases generated by more natural soil processes) to get to the atmosphere and/or, less comprehensibly, that the addition of organic effluent into the STU area is somehow promoting conditions for the soil to act as a net $\mathrm{CO}_{2}$ sink, possibly by changing the microbial diversity within the soil, leading to accumulation of organics. It should also be noted that sections of the STU where the pipes are located have had $500 \mathrm{~mm}$ of soil replaced by gravel, missing soil compared to the control sites that would be contributing to $\mathrm{CO}_{2}$ fluxes if present. The relative effect size of both differences was moderate, with 0.59 and 0.50 for PE and SE, respectively. The difference between pre-treatment levels was small, but significant $\left(p_{\text {adj }}<0.001\right)$.

For $\mathrm{CH}_{4}$, the undisturbed control soil expressed a net median uptake of $-0.42 \mathrm{nmolCH}_{4} \mathrm{~m}^{-2} \mathrm{~s}^{-1}$, a significantly higher uptake than observed over the STU for both trenches receiving $\mathrm{PE}\left(\mathrm{Md}=-0.30 \mu \mathrm{molCH} \mathrm{CH}_{4} \mathrm{~m}^{-2} \mathrm{~s}^{-1}, p_{\text {adj }}<0.001\right)$ and trenches receiving SE $\left(\mathrm{Md}=-0.37 \mu \mathrm{molCH}_{4} \mathrm{~m}^{-2} \mathrm{~s}^{-1}\right.$, $p_{\text {adj }}=0.003$ ) even though both STUs were also net sinks (see Table S5). The relative effect size of both differences was moderate to low, with 0.40 and 0.10 for PE and SE, respectively, and the difference between pre-treatment levels was relatively small in absolute terms, yet significant $\left(p_{\text {adj }}<0.001\right)$, with a moderate effect size of 0.41 . Despite the overall range of fluxes observed from the control soil being comparable to the range of fluxes from $\mathrm{PE}$ trenches, only $0.3 \%$ of control fluxes were higher than $2 \mu \mathrm{molCH}_{4} \mathrm{~m}^{-2} \mathrm{~s}^{-1}$, compared to $14.6 \%$ and $2.0 \%$ for PE and SE trenches, respectively. This suggests that the relatively high abundance of high-emission events over PE trenches must have been the main driver of the difference 

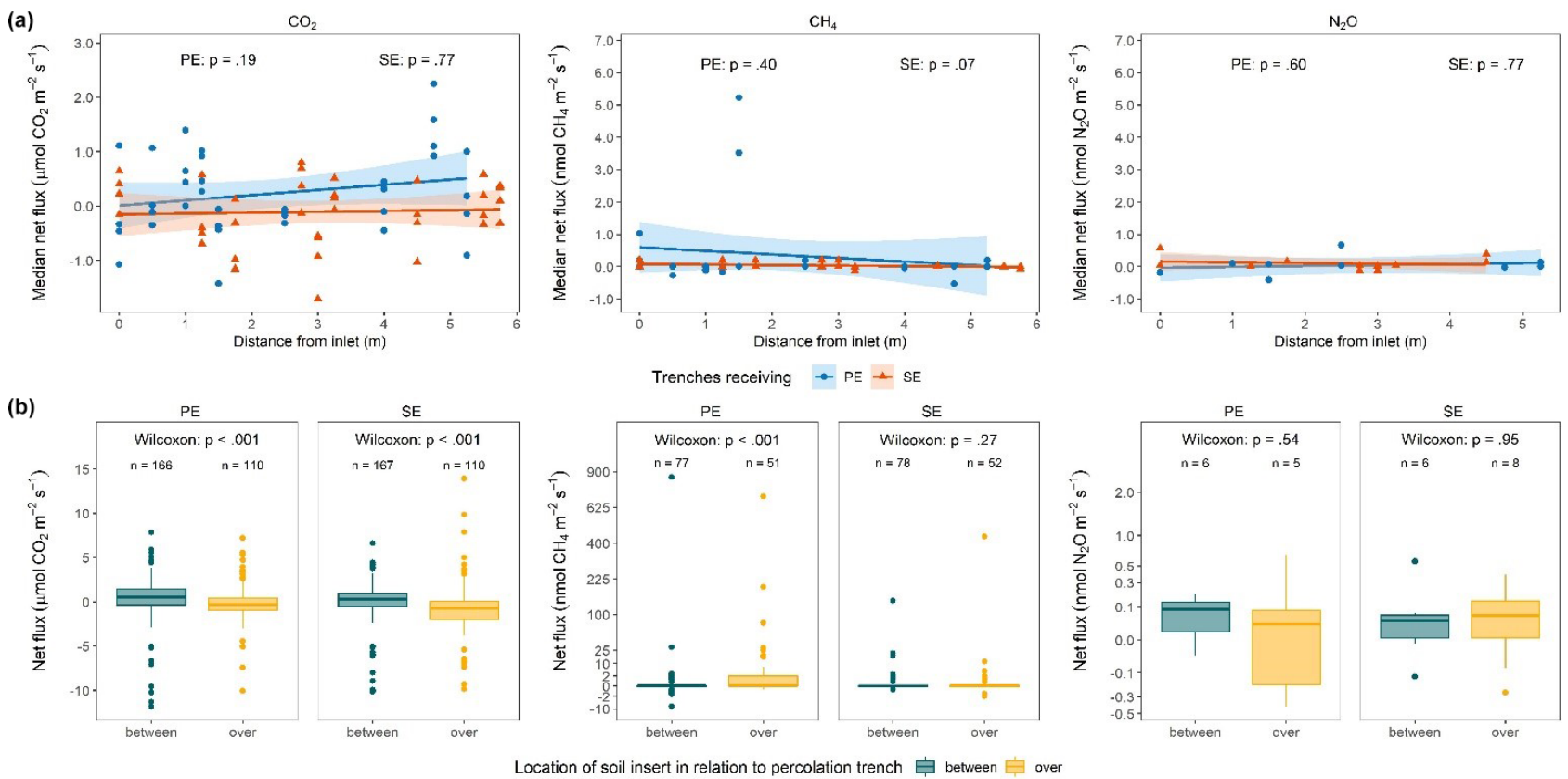

Figure 3. (a) Quarterly median fluxes observed by discrete GHG measurements over the STU as a function of distance from the inlet for trenches receiving PE (blue circles) and SE (red pyramids). Linear fits are marked by solid lines. The shaded areas represent the standard error of the fit. (b) Boxplots comparing net fluxes observed by discrete GHG measurements over the STU from soil inserts located either between (blue) or over (red) gravel trenches. Statistical results are presented as the $p$ value of Wilcoxon signed rank tests; $n$ denotes the number of observations per group. Note that in both subfigures the $y$ scale for $\mathrm{CO}_{2}$ is given in units different from units used for $\mathrm{CH}_{4}$ and $\mathrm{N}_{2} \mathrm{O}$ and that the $y$ axis for $\mathrm{CH}_{4}$ and $\mathrm{N}_{2} \mathrm{O}$ has been square-root transformed in panel (b) to improve data visualisation.

between PE and SE trenches, emphasising the importance of capturing the entire range of potential fluxes.

\subsubsection{Diurnal patterns}

$\mathrm{CO}_{2}$ fluxes expressed distinct diurnal variations, with median peaks in the early afternoon at 15:00, 14:00 and 12:00 for the control soil and PE and SE trenches, respectively (Fig. 4a). The lowest median $\mathrm{CO}_{2}$ fluxes occurred during the early morning hours at 05:00, 06:00 and 06:00 for the control soil and PE and SE trenches, respectively. This pattern implies a strong dependence of $\mathrm{CO}_{2}$ fluxes on diurnal temperature variations, independent of treatment, with peaks occurring at approximately the same time (05:00 and 15:00 for minimum and maximum mean temperature, respectively), which is, in turn, correlated with microbial activity. It has to be noted, however, that control fluxes were most strongly affected by mid-day positive flux peaks compared to STU fluxes, which are probably damped by some the gas finding an alternative route to the atmosphere along the trenches and up through the vent pipes, as mentioned above. $\mathrm{CH}_{4}$ flux, on the other hand, expressed only weak to no diurnal patterns (Fig. 4a), indicating that other factors than temperature, such as substrate availability, methanotrophic activity or changes in water content, must have been the main drivers responsible for $\mathrm{CH}_{4}$ fluxes as suggested by, for example, Fernández-Baca et al. (2018), Somlai et al. (2019), Swenson et al. (2019) and Truhlar et al. (2019).

\subsubsection{Seasonal patterns}

Apart from diurnal variations, GHG fluxes also followed seasonal patterns, with fluxes generally higher in warmer summers compared to colder winters. Both sites were located in the west of Ireland where the relatively strong maritime influence leads to cool and windy winters and mostly mild and less windy summers, with similar rainfall quantities across the year. $\mathrm{CO}_{2}$ fluxes exhibited a clear temperature dependence, with lower fluxes with narrower ranges during the colder months (from September until February) and higher fluxes with wider ranges over the warmer months. For $\mathrm{CO}_{2}$, seasonal variation was highest for the control soil, with median summer fluxes $\left(\mathrm{Md}=6.47 \mu \mathrm{molCO}_{2} \mathrm{~m}^{-2} \mathrm{~s}^{-1}\right)$ being approximately 16 times higher than median winter fluxes $\left(\mathrm{Md}=0.40 \mu \mathrm{molCO} \mathrm{Cm}_{2} \mathrm{~m}^{-2} \mathrm{~s}^{-1}\right.$. Median STU fluxes for both $\mathrm{PE}$ and $\mathrm{SE}$ trenches only expressed a 5 -fold increase from 0.81 and 0.72 to 3.90 and $3.82 \mu \mathrm{mol} \mathrm{CO}_{2} \mathrm{~m}^{-2} \mathrm{~s}^{-1}$ from the lowest to highest flux season, respectively (Fig. 4b). During the summer months (June, July and August), the fluxes from the control area exceeded the fluxes from the surface of the STU. Despite the relative difference in the absolute magnitude of the seasonal effect, the relative distribution of fluxes remained mostly constant through- 
(a)
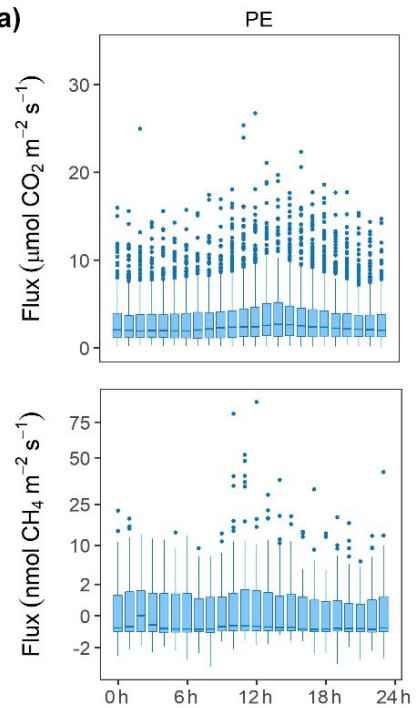

Location PE

(b)
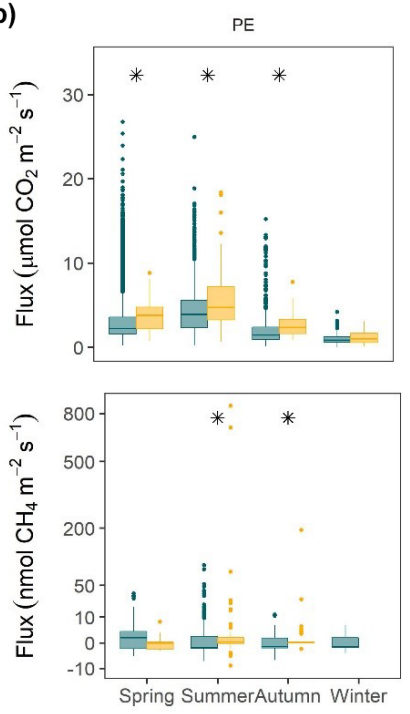
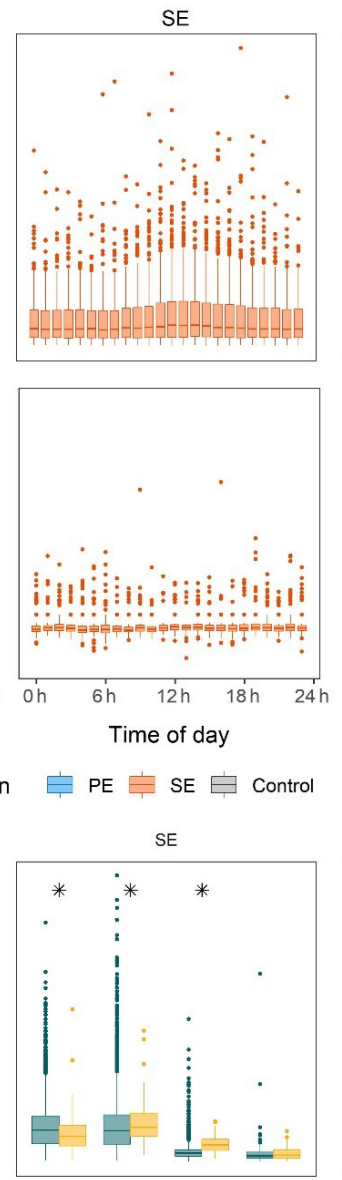

Time of day

SE

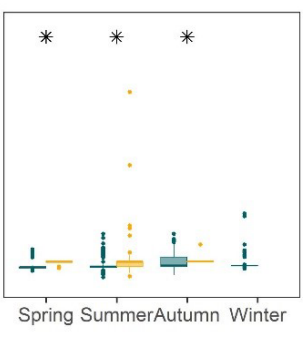

Season
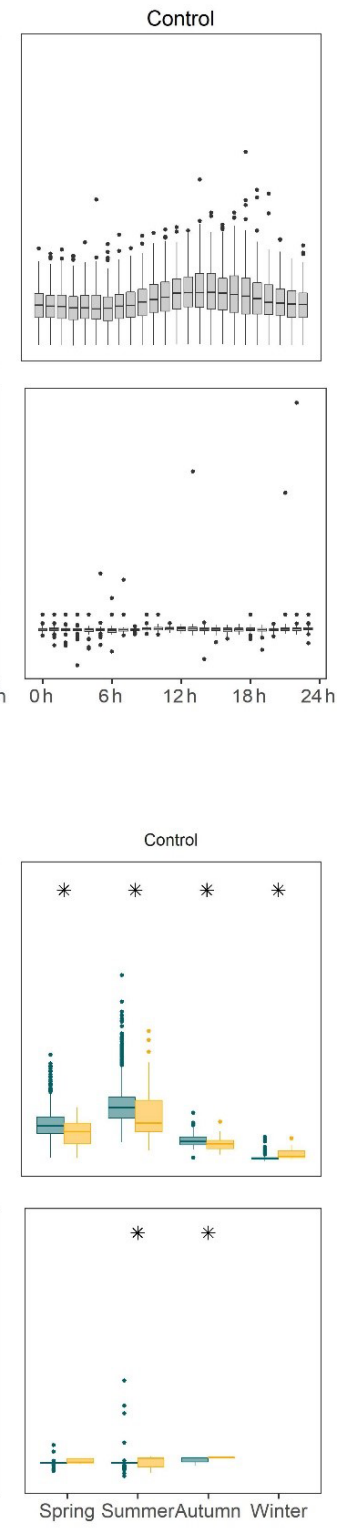

Chamber deployment $\quad$ continuous $\square$ discrete

Figure 4. (a) Boxplots of diurnal patterns of observed fluxes over trenches receiving PE, trenches receiving SE and undisturbed soil as Control for $\mathrm{CO}_{2}$ and $\mathrm{CH}_{4}$. (b) Boxplots comparing seasonal patterns of observed fluxes from continuous (blue) and discrete (red) measurements over trenches receiving PE, trenches receiving SE and undisturbed soil as Control for $\mathrm{CO}_{2}$ and $\mathrm{CH}_{4}$. Groups marked with an asterisk had significantly different fluxes observed from both measurement approaches (Wilcoxon signed rank test). Note that in both subfigures the $y$ scale for $\mathrm{CO}_{2}$ is given in units different from units used for $\mathrm{CH}_{4}$ and that the $y$ axis for $\mathrm{CH}_{4}$ has been square-root transformed to improve data visualisation.

out all seasons and across all types, with approximately $35 \%$ to $47 \%$ of total emissions originating from the upper quartile of observed fluxes. For $\mathrm{CH}_{4}$, the picture is more complex. While the control soil and trenches receiving PE expressed the highest median $\mathrm{CH}_{4}$ uptake rates in the summer $\left(-0.43\right.$ and $-0.37 \mu \mathrm{molCH}_{4} \mathrm{~m}^{-2} \mathrm{~s}^{-1}$, respectively), STU trenches receiving SE expressed the highest me- dian $\mathrm{CH}_{4}$ uptake rates in spring $\left(-0.50 \mu \mathrm{molCH} \mathrm{CH}_{4} \mathrm{~m}^{-2} \mathrm{~s}^{-1}\right)$ and the lowest median $\mathrm{CH}_{4}$ uptake rates in autumn $\left(-0.20 \mu \mathrm{molCH}_{4} \mathrm{~m}^{-2} \mathrm{~s}^{-1}\right)$. In comparison, the control soil appeared to be neutral $\left(\mathrm{Md}=0.00 \mu \mathrm{molCH}_{4} \mathrm{~m}^{-2} \mathrm{~s}^{-1}\right)$ and the soil over trenches receiving PE a gross emitter of $\mathrm{CH}_{4}$ $\left(\mathrm{Md}=0.40 \mu \mathrm{molCH}_{4} \mathrm{~m}^{-2} \mathrm{~s}^{-1}\right.$ in spring) (Fig. $4 \mathrm{~b}$ ). Figure $4 \mathrm{~b}$ also shows a comparison of the fluxes from the discrete ver- 


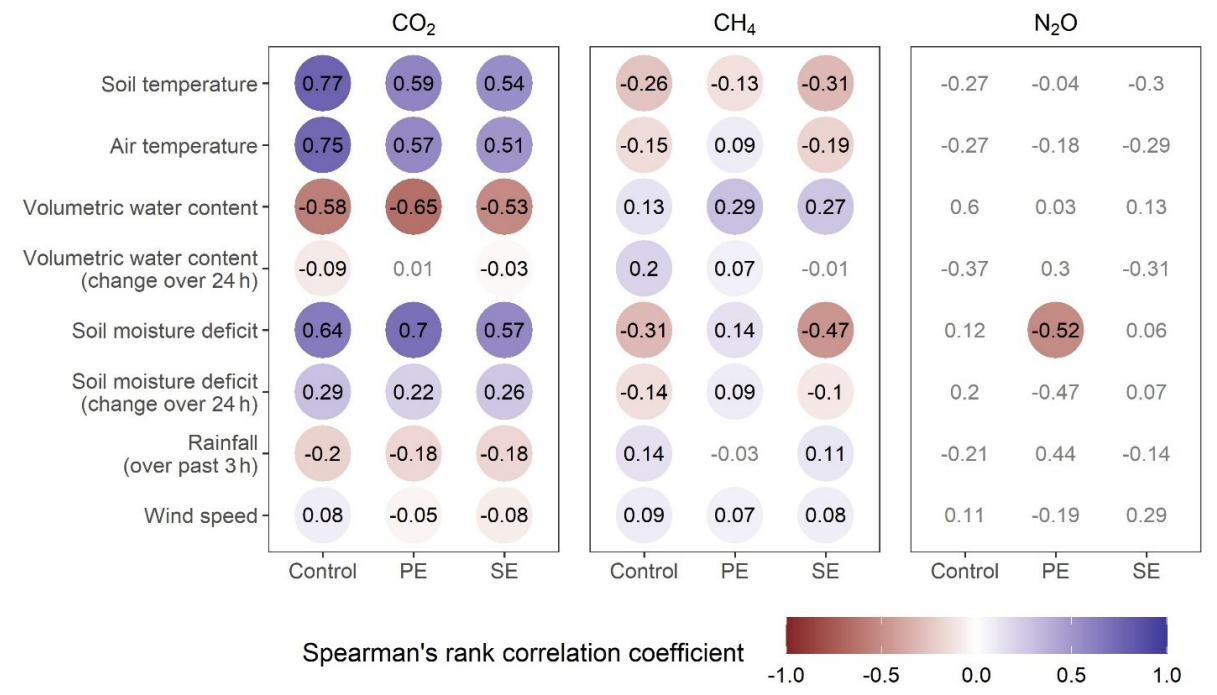

Figure 5. Correlograms of observed fluxes over the $\mathrm{STU}$ for $\mathrm{CO}_{2}, \mathrm{CH}_{4}$ and $\mathrm{N}_{2} \mathrm{O}$ to selected environmental parameters. The numerical value and fill colour correspond to Spearman's rank correlation coefficient where the correlation was significant (i.e. $p \leq 0.05$ ). Grey numerical values without coloured circles represent correlations that were not significantly different from zero (i.e. $p>0.05$ ).

sus the continuous measurement above the STUs. Significant differences (indicated by asterisks) are shown in spring, summer and autumn, with discrete measurements generally higher than the continuous measurements. However, the opposite was found for the control measurements where the continuous measurements were higher than discrete measurements, which perhaps can be attributed to the time of day when discrete measurements were taking place being more aligned with when effluent was being discharged to the STUs.

Notably, during this study in summer 2018 there was an unusually long period of drought which lasted for approximately 3 months, which caused severe drying of the soil and soil moisture deficit at both sites (Knappe et al., 2020). The extended drought conditions increased daily median $\mathrm{CO}_{2}$ fluxes over all areas. In summer 2018, daily median $\mathrm{CO}_{2}$ fluxes from STU trenches receiving PE, SE and the control soil increased to approximately $450 \%, 130 \%$ and $160 \%$, respectively, in comparison to the month preceding the drought conditions (Table S6 in the Supplement). $\mathrm{CH}_{4}$ flux measurements were not conducted during this period. The increases were significant for all three locations, with large effect size for trenches receiving $\mathrm{PE}(p=<0.001 ; \bar{r}=0.86[0.85$; $0.86])$ and the control $(p=<0.001 ; \bar{r}=0.79[0.65 ; 0.74])$ and small effect size for trenches receiving SE $(p=0.03$; $\bar{r}=0.29[0.03 ; 0.50])$. As $\mathrm{CO}_{2}$ emissions from microbial respiration in the soil tend to be governed by soil temperature over a wide range of soil moisture contents but become a function of moisture content as the soil dries out (Smith et al., 2003), the extended dry conditions with soil moisture deficit (SMD) of up to $75 \mathrm{~mm}$ and VWC of $<21 \%$ as experienced on both sites will lead to increased gas fluxes. The stronger relative flux increases over trenches receiving PE could be related to generally wetter conditions observed at the infiltrative layer compared to trenches receiving SE (Knappe et al., 2020), thus not leading to moisture-limited gas flux conditions at depth. This becomes evident when comparing flux correlations with environmental factors (Figs. 5 and S3 in the Supplement). While overall $\mathrm{CO}_{2}$ fluxes were strongly positively correlated with temperature and SMD, and strongly negatively correlated with VWC, fluxes during the drought expressed overall weaker correlations to these environmental factors and were even slightly negatively correlated with soil temperature and slightly positively correlated with VWC over trenches receiving PE. This indicates that the presence of sufficient levels of moisture content in the soil became the dominant driver under these conditions.

\subsubsection{Environmental drivers of GHG fluxes}

To assess environmental drivers of observed GHG fluxes, a correlation analysis between fluxes and environmental parameters relating to air and soil temperature, volumetric water content and soil moisture deficit, rainfall, and wind speed was performed using Spearman's rank correlation coefficient (Fig. 5). Overall, $\mathrm{CO}_{2}$ fluxes showed the most consistent correlations across both control and STU trenches, suggesting that environmental factors were the main driver for controlling $\mathrm{CO}_{2}$ emissions, as opposed to treatment-specific differences. $\mathrm{CO}_{2}$ fluxes were strongly positively correlated with both soil and air temperature presumably linked to faster kinetics of microbial activity with increased temperature, albeit with a generally stronger effect over the control (Spearman $\rho=0.75$ to 0.77 ) compared to STU trenches (Spearman $\rho=0.51$ to 0.59 ). The similarity between the two temperature measurements was to be expected as the soil temperature 
measurements, which are commonly conducted alongside flux chamber measurements, were taken within the first $5 \mathrm{~cm}$ in the shallow soil and, thus, should follow a muted but similar pattern with respect to ambient temperature conditions. Similar in magnitude but opposite in direction were correlations relating to the monitored value of VWC (Spearman $\rho=-0.65$ to -0.53 ) and calculated value of SMD (Spearman $\rho=0.57$ to 0.70 ), indicating that drier conditions led to higher $\mathrm{CO}_{2}$ fluxes, independent of measuring location. Considering changes in both water content and SMD over the preceding $24 \mathrm{~h}$, however, it becomes evident that drying events in already relatively dry soil (i.e. when $\triangle \mathrm{SMD}>0$ ) were correlated to higher $\mathrm{CO}_{2}$ fluxes than water content changes at more saturated conditions (Fig. 5). Correlations to wind speed and $3 \mathrm{~h}$ accumulated rainfall prior to measurement remained weak. More unsaturated conditions will enhance oxygen transfer into the soil biofilms, thereby improving external mass transfer and the overall kinetics of microbial respiration and conversion of organics to $\mathrm{CO}_{2}$.

For $\mathrm{CH}_{4}$ fluxes, correlations to environmental parameters were generally weaker and often in the opposite direction when compared to $\mathrm{CO}_{2}$ fluxes. Colder temperatures corresponded generally with $\mathrm{CH}_{4}$ uptake and warmer temperatures with $\mathrm{CH}_{4}$ release for control and SE trench fluxes (Spearman $\rho=-0.31$ to -0.15 ). The soil's volumetric water content affected STU fluxes more strongly (Spearman $\rho=0.27$ to 0.29 ) than the control (Spearman $\rho=0.13$ ), which also had less overall variability in both water content and observed fluxes (Fig. 5). Considering the changes in SMD, it becomes evident that high- $\mathrm{CH}_{4}$-emission events remained largely limited to periods when the soil in the STU starts to dry out from being nearly saturated. Similar patterns were previously reported from gravel-filled soakaways in Ireland (Somlai et al., 2019). While stable dry conditions were generally marked by lower net fluxes and net $\mathrm{CH}_{4}$ uptake over the STU, wetting events only caused considerable $\mathrm{CH}_{4}$ fluxes from trenches receiving PE. The weaker correlation between transitional soil moisture conditions compared to $\mathrm{CO}_{2}$ fluxes suggests that $\mathrm{CH}_{4}$ fluxes are more susceptible to short-term changes and immediate soil conditions, which is in line with observations by Fernández-Baca et al. (2020), who found both STU and control soils to be either weak sinks or weak sources of $\mathrm{CH}_{4}$, except for periods of changing soil moisture conditions where they became net sources over the first $30 \mathrm{~min}$ following a simulated rain event. Truhlar et al. (2016) also observed increasing soil $\mathrm{CH}_{4}$ fluxes with increasing VWC, attributing it to the fact that with the methanotrophs are aerobic bacteria, whereas methanogens are anaerobic. This also aligns with more general findings of higher $\mathrm{CH}_{4}$ emissions and uptake rates under changing soil moisture conditions, as well as with increasing temperature (Swenson et al., 2019; Le Mer and Roger, 2001).

Due to the limited amount of available $\mathrm{N}_{2} \mathrm{O}$ fluxes, which only resulted from discrete measurements, correlations were not significantly different from zero for all parameters and treatment except for a moderate negative correlation between $\mathrm{N}_{2} \mathrm{O}$ fluxes over trenches receiving $\mathrm{PE}$ and the SMD (Spearman $\rho=-0.53$ ). However only a few measurements occurred at high SMD values, i.e. dry conditions (Fig. 5). Truhlar et al. (2016) and Fernández-Baca et al. (2020) found the STU to be net producers of $\mathrm{N}_{2} \mathrm{O}$ immediately after rain events; a similar trend was observed over trenches receiving PE where $60 \%$ of $\mathrm{N}_{2} \mathrm{O}$ emission events were recorded after rainfall events within the preceding $3 \mathrm{~h}$. Studies in other land use scenarios and soil columns have also found positive correlations between $\mathrm{N}_{2} \mathrm{O}$ emissions and soil moisture (Ambus and Christensen, 1995; Smith et al. 1998; Anderson et al., 2019), whereby maybe the rapidly changing soil moisture and redox conditions in the soils disrupt the balance of the microbial soil community, leading to periods of partial dentification.

\subsection{Fluxes from the vents}

The STU vent system consists of pipes extending approximately $1 \mathrm{~m}$ from the ground surface at the end of percolation trenches. Each vent is directly connected to the perforated effluent distribution pipe within the trench by a $90^{\circ}$ elbow and capped with a perforated vent cap. Gases originating within both the distribution pipe itself (e.g. from biofilm growth within the pipe itself) and the trench (i.e. through the pipe perforation) can escape through the vent system.

For $\mathrm{CO}_{2}$, significantly higher $(p=0.05)$ median fluxes from the vent system were observed over trenches receiving $\quad \mathrm{PE} \quad\left(\mathrm{Md}=4.91 \quad[2.69 ; \quad 7.61] \mu \mathrm{molCO}_{2} \mathrm{~s}^{-1}\right)$ compared to trenches receiving $\mathrm{SE}(\mathrm{Md}=2.58$ [2.07; 3.88] $\mu \mathrm{molCO}_{2} \mathrm{~s}^{-1}$ ) with peaks of up to 170.15 and $47.75 \mu \mathrm{molCO} \mathrm{CO}_{2} \mathrm{~s}^{-1}$, respectively, indicating that a small number of high-emission events are responsible for the majority of total observed emissions (Fig. 6). The upper quartile of observed fluxes contributed $80.6 \%$ and $65.5 \%$ of the total recorded emissions, for the PE and SE trenches, respectively. Despite generally lower overall fluxes at Site A compared to Site B, both sites expressed similar patterns between treatments (PE vs. SE; Fig. S3). Additionally, fluxes at Site B were marked by a small number of extremely high fluxes (up to 27 times and 18 times higher than median fluxes from trenches receiving PE and SE, respectively). These peaks were generally less pronounced at Site A. The high variability in observed fluxes resulted in a relatively large uncertainty of the overall effect size of this difference between both treatments, ranging from nearly no to moderate effect $(\bar{r}=0.23[0.02 ; 0.46])$ of pre-treatment level on observed $\mathrm{CO}_{2}$ fluxes.

Similarly, for $\mathrm{CH}_{4}$, significantly higher $(p=0.003)$ median fluxes from the vent system were observed over trenches receiving PE $\left(\mathrm{Md}=2.59[0.23 ; 11.0] \mathrm{nmolCH}_{4} \mathrm{~s}^{-1}\right)$ in comparison to trenches receiving $\mathrm{SE}(\mathrm{Md}=-0.06[-0.23$; $0.05] \mathrm{nmolCH}_{4} \mathrm{~s}^{-1}$, where a small net uptake was observed as a result of lower-than-ambient $\mathrm{CH}_{4}$ concentrations within 


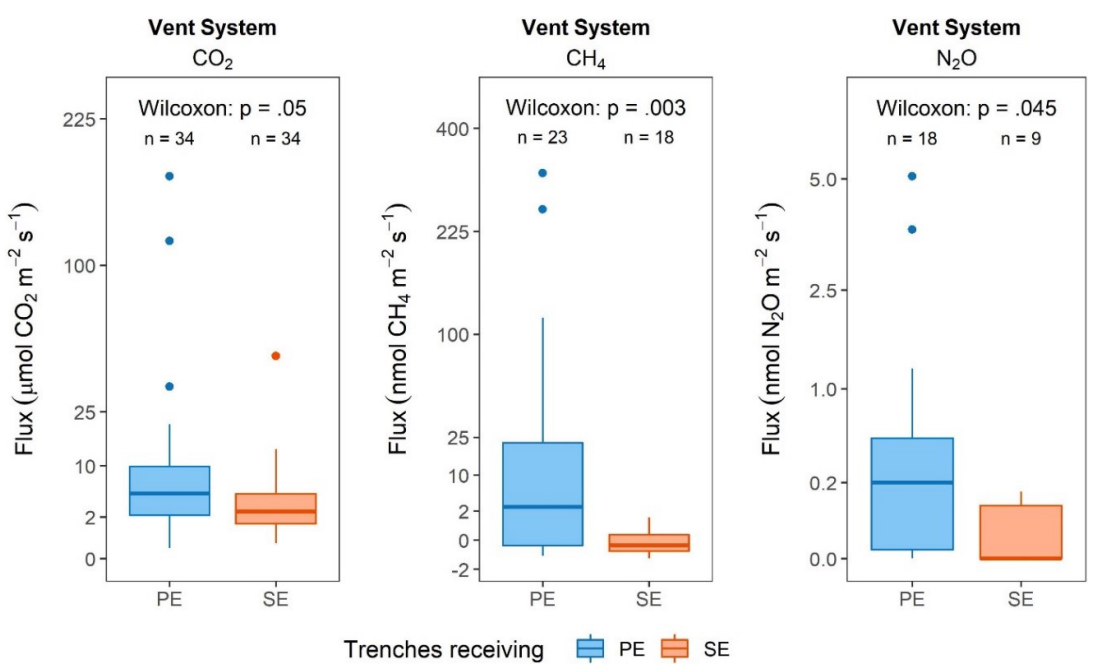

Figure 6. Boxplots of observed gas fluxes from the STU vent system for $\mathrm{CO}_{2}, \mathrm{CH}_{4}$ and $\mathrm{N}_{2} \mathrm{O}$ over trenches receiving primary (PE) and secondary (SE) effluent. Statistical results are presented as the $p$ value of Wilcoxon signed rank tests with estimated effect size $r$ and corresponding boot-strapped $95 \%$ confidence intervals; $n$ denotes the number of observations per group. Note that the $y$ scale for $\mathrm{CO}_{2}$ is given in units different from units used for $\mathrm{CH}_{4}$ and $\mathrm{N}_{2} \mathrm{O}$ and that the $y$ axis has been square-root transformed to improve data visualisation.

the vent system (Fig. 6). It is unlikely that this gradient actually led to a passive uptake of $\mathrm{CH}_{4}$ from the natural environment. It is more likely a result of constant diffusion of $\mathrm{CH}_{4}$, which is less dense than air, thus escaping more readily through the vent system compared to $\mathrm{CO}_{2}$, indicating that while the exact long-term $\mathrm{CH}_{4}$ emissions from the vent system might not be effectively captured by discrete measurements alone, trenches receiving effluent of low organic strength might not be significant producers of net $\mathrm{CH}_{4}$ emissions. However, peak fluxes of up to 318.0 and $1.20 \mathrm{nmolCH}_{4} \mathrm{~s}^{-1}$ for trenches receiving PE and SE, respectively, suggest that, at least for trenches receiving PE, periodic high-emission events determine the majority of observed total emissions (as discussed previously in Sect. 3.3.6) with the upper quartile of observed fluxes contributing $85.8 \%$ to the total recorded $\mathrm{CH}_{4}$ emissions. Despite generally lower overall fluxes at Site A compared to Site B, both sites expressed similar patterns between treatments (PE vs. SE; Fig. S4 in the Supplement). The observed effect $(\bar{r}=0.46[0.16 ; 0.67])$ of pre-treatment on $\mathrm{CH}_{4}$ fluxes from the vent system was stronger than for $\mathrm{CO}_{2}$ fluxes, likely due to the relatively small spread of fluxes observed from SE trenches.

For $\mathrm{N}_{2} \mathrm{O}$, significantly higher $(p=0.045)$ median fluxes from the vent system were observed over trenches receiving $\mathrm{PE}\left(\mathrm{Md}=0.41[-0.02 ; 0.49] \mathrm{nmolN}_{2} \mathrm{O} \mathrm{s}^{-1}\right)$ compared to trenches receiving $\mathrm{SE}(\mathrm{Md}=0.101$ [0.001; $0.102] \mathrm{nmolN}_{2} \mathrm{O} \mathrm{s}^{-1}$ ) (Fig. 6). However, the inclusion of zero within the estimated confidence intervals around the median suggest that, despite higher emissions from PE trenches, emissions from both trench types appear to be periodic in nature. Peak $\mathrm{N}_{2} \mathrm{O}$ fluxes of up to 5.07 and $0.16 \mathrm{nmol}_{2} \mathrm{O} \mathrm{s}^{-1}$ were observed from the vents connected to trenches receiving $\mathrm{PE}$ and $\mathrm{SE}$, respectively. As with $\mathrm{CH}_{4}$, a large proportion $(82.1 \%)$ of the total recorded emissions stem from only the upper quartile of observed fluxes from PE trenches. Again, generally lower overall fluxes were recorded at Site A compared to Site B, but both sites expressed similar patterns between treatments (PE vs. SE; Fig. S3). Similar to $\mathrm{CO}_{2}$ and $\mathrm{CH}_{4}$, fluxes at Site B were marked by a small number of extremely high flux events (up to 12 times higher than the median fluxes from the PE receiving trenches). These peaks were generally less pronounced at Site A. Increasing the number of measurements in future studies should help elucidate if the difference is indeed significant over the long-term or just an artefact of the limited number of samples collected in this study. The overall effect size $(\bar{r}=0.39[0.07 ; 0.65])$ of the level of pre-treatment on observed $\mathrm{N}_{2} \mathrm{O}$ fluxes was small to moderate and similar to the one observed for $\mathrm{CH}_{4}$. Similarly, these findings suggest that the exact long-term dynamics from the vent system might not be effectively captured by discrete measurements as trenches receiving effluent low in $\mathrm{TN}$ might not be producers of detectable $\mathrm{N}_{2} \mathrm{O}$ fluxes.

In summary, vent system fluxes of all three gases were generally higher from trenches receiving PE with higher organic and TN load compared to trenches receiving lowerstrength SE. This is believed to be a consequence of both the higher substrate availability for microbial degradation processes taking place within the STU trench (thus leading to higher $\mathrm{C}$ and $\mathrm{N}$ turnover) and the improved effluent dispersal along the trench due to the development of a longer and less permeable biomat at the infiltrative surface of PE trenches (thus extending the microbially active zone further along the trench, i.e. closer to the vent; see Knappe et al., 2020). 
Table 2. Total net greenhouse gas emissions from the two different treatment configurations: septic tank-STU (PE) and septic tankpackaged secondary treatment system-STU (SE). All emissions are given in $\mathrm{kg}-\mathrm{CO}_{2}$ eq. $\mathrm{cap}^{-1} \mathrm{yr}^{-1}$.

\begin{tabular}{|c|c|c|c|c|c|}
\hline \multicolumn{2}{|c|}{$\mathrm{CO}_{2}$ eq. emissions } & \multirow[t]{2}{*}{ ST } & \multicolumn{2}{|c|}{ STU (surface and vents) } & \multirow[t]{2}{*}{ Total } \\
\hline & & & Surface & Vents & \\
\hline \multirow[t]{4}{*}{$\mathrm{PE}$} & $\mathrm{CO}_{2}$ & 2.97 & -2.78 & 6.06 & 6.25 \\
\hline & $\mathrm{CH}_{4}$ & 2.72 & 0.00 & 0.03 & 2.75 \\
\hline & $\mathrm{N}_{2} \mathrm{O}$ & 0.00 & 0.86 & 0.13 & 0.99 \\
\hline & Total & 5.69 & -1.92 & 6.22 & 9.99 \\
\hline \multirow[t]{4}{*}{ SE } & $\mathrm{CO}_{2}$ & 2.97 & -8.91 & 3.18 & -2.76 \\
\hline & $\mathrm{CH}_{4}$ & 2.72 & 0.00 & 0.00 & 2.72 \\
\hline & $\mathrm{N}_{2} \mathrm{O}$ & 0.00 & 0.57 & 0.02 & 0.59 \\
\hline & Total & 5.69 & -8.33 & 3.20 & 0.55 \\
\hline
\end{tabular}

These relatively high fluxes coming out of the vents would seem to reinforce the findings on the STUs of higher fluxes picked up over the percolation trenches than between them (see Sect. 3.4), indicating that the gases are finding an easier escape route to the atmosphere via the vents in those regions rather than up through the soil. Indeed, other studies on the sites investigating the transformation of organics in the STUs showed that the main reduction in organic $C$ occurs just below the infiltrative surface whereby protein-like compounds in the effluent are removed, leaving more recalcitrant organics with a higher degree of humification and aromaticity to percolate further down through the soil (Dubber et al., 2021) As the vent system is directly connected to the pore space within STU trenches, temperature gradients between the subsurface trench and the atmosphere as well as wind over the vents will cause an upward draw of air from the vent. Fluxes are, thus, expected to be highly variable on timescales of minutes to hours. This corroborates the previous findings that continuous or semi-continuous measurements are much more likely to detect periods of high fluxes (Somlai-Haase et al., 2017; Somlai et al., 2019; Truhlar et al., 2019). Vent flux values obtained from discrete measurements are, thus, challenging to compare between sites.

The observed vent system fluxes of all three gases were similar to emissions from DWWTS vent systems found in previous studies. For example, Diaz-Valbuena et al. (2011) reported fluxes of $54.4 \mu \mathrm{mol} \mathrm{CO}_{2} \mathrm{~s}^{-1}$ from vents located over the pipe leading from the ST to the STU, which would result in fluxes of $13.7 \mu \mathrm{molCO}_{2} \mathrm{~s}^{-1}$ per trench if the effluent was split between four STU trenches as in this study. However, the same study found $\mathrm{CH}_{4}$ and $\mathrm{N}_{2} \mathrm{O}$ fluxes to be negligible from the same vent.

\subsection{Total GHG emissions - comparison between treatment configurations}

The total estimated net emissions from the full systems (septic tanks, STUs and vent pipes) have been calculated by assuming that all four trenches receive either only PE or only $\mathrm{SE}$ and that the biomat had spread to $15 \mathrm{~m}$ in $\mathrm{PE}$ trenches and $8.75 \mathrm{~m}$ in SE trenches (see Knappe et al., 2020). A comparison has been made at each site to evaluate how the inclusion of up-front packaged secondary treatment units impacts the net emissions from the STUs (see Table 2). Averaged across both sites, the total net emissions from the STUs (including vent systems) equate to $9.99 \mathrm{~kg}-\mathrm{CO}_{2}$ eq. $\mathrm{cap}^{-1} \mathrm{yr}^{-1}$ assuming all four trenches receive $\mathrm{PE}$ compared to $0.55 \mathrm{~kg}-\mathrm{CO}_{2}$ eq. cap $^{-1} \mathrm{yr}^{-1}$ from the full system assuming all four trenches receive SE. Again, it is important to note here that emission rates were not measured from the packaged secondary treatment units directly, and so they have not been included in this calculation. There are tens of different secondary units commercially available on the market, based on different secondary treatment processes (suspended growth systems, biofilm based and hybrid systems) with different hydraulic configurations. Thus an assessment of this treatment step would be very systemspecific, and emissions will vary between the available technology options. It should also be noted that at Site B, the difference between emissions from the STUs receiving PE and $\mathrm{SE}$ was significant, whereas at Site A, there was no significant difference between the two total net emissions, reflecting the poorer secondary treatment performance of the up-front packaged treatment plant at Site A.

For the more common septic tank and STU (PE) DWWTS configuration, which accounts for $89 \%$ of DWWTSs in Ireland for example, $62.6 \%, 27.5 \%$ and $9.9 \%$ of the total net emissions were in the form of $\mathrm{CO}_{2}, \mathrm{CH}_{4}$ and $\mathrm{N}_{2} \mathrm{O}$ (when converted to $\mathrm{CO}_{2}$ eq.).

From a treatment train perspective, the total estimated annual $\mathrm{CO}_{2}$ emissions from the STs were $2.97 \mathrm{~kg}-\mathrm{CO}_{2} \mathrm{cap}^{-1} \mathrm{yr}^{-1}$, with higher $\mathrm{CO}_{2}$ emissions in the first chamber at both sites. The total estimated annual $\mathrm{CH}_{4}$ emissions from the STs were $2.72 \mathrm{~kg}-\mathrm{CO}_{2}$ eq. $\mathrm{cap}^{-1} \mathrm{yr}^{-1}$, with higher $\mathrm{CH}_{4}$ emissions in the second chamber at Site A and higher $\mathrm{CH}_{4}$ emissions in the first chamber at Site B. As stated previously, these emissions from the ST may be biased towards underestimating the actual emissions as those were mainly based on discrete measurements.

From the surface of the STUs, the total annual $\mathrm{CO}_{2}$ eq. emissions estimated for the areas receiving $\mathrm{PE}$ were $-1.92 \mathrm{~kg}-\mathrm{CO}_{2}$ eq. $\mathrm{cap}^{-1} \mathrm{yr}^{-1}$, i.e. slightly less compared to emissions from the adjacent native soil. However, this is thought to be mainly caused by the percolation trenches acting to channel some of the microbially produced gases within the STUs out to the vents, which equated to total annual $\mathrm{CO}_{2}$ eq. emissions of $6.22 \mathrm{~kg}^{-\mathrm{CO}_{2}}$ eq. $\mathrm{cap}^{-1} \mathrm{yr}^{-1}$, primarily in the form of $\mathrm{CO}_{2}$. In the more lightly or- 
ganically loaded STUs receiving SE there was a much greater deficit between the emissions from the surface of the STU compared to the adjacent undisturbed soil, equating to $-8.33 \mathrm{~kg}-\mathrm{CO}_{2}$ eq. $\mathrm{cap}^{-1} \mathrm{yr}^{-1}$. When the total annual $\mathrm{CO}_{2}$ eq. emissions from the vent systems receiving $\mathrm{SE}$ of $3.20 \mathrm{~kg}-\mathrm{CO}_{2}$ eq. $\mathrm{cap}^{-1} \mathrm{yr}^{-1}$ are taken into account, this still shows overall lower emissions equivalent to $-5.14 \mathrm{~kg}-\mathrm{CO}_{2}$ eq. cap ${ }^{-1} \mathrm{yr}^{-1}$ compared to the native soil, which suggests that either the lower-strength organic effluent entering the STU is leading to a change in microbial diversity within the soil and thereby different net emissions and/or the gases are finding an alternative pathway to the atmosphere, possibly back up via the distribution boxes at the head of the trenches as the active biomat was shown to extend only for the first few metres in these SE-fed trenches. As mentioned, $\mathrm{CO}_{2}$ emissions were not measured from the secondary treatment plants themselves due to access restrictions into the modules, but presumably these would be significant due to the reduction in organics in the effluent that occurs within them. The impact of the difference in performance between the different packaged secondary treatment units on the two sites was clearly picked up with higher emissions from trenches receiving SE at Site A and slightly higher emissions from trenches receiving PE at Site B.

A comparison of the net GHG emissions from the septic tank and STU (9.99 kg-CO ${ }_{2}$ eq. $\mathrm{cap}^{-1} \mathrm{yr}^{-1}$ ) against other similar studies of on-site wastewater treatment reveals much lower fluxes. Diaz-Valbuena et al (2011) estimated total GHG emissions from septic tanks and vent systems (but did not measure fluxes directly above the STU) of 101 to $119 \mathrm{~kg}-\mathrm{CO}_{2}$ eq. $\mathrm{cap}^{-1} \mathrm{yr}^{-1}$, whilst Truhlar et al (2016) estimated even higher total GHG emissions of $270 \mathrm{~kg}-\mathrm{CO}_{2}$ eq. cap ${ }^{-1} \mathrm{yr}^{-1}$ (with $50 \mathrm{~kg}-\mathrm{CO}_{2}$ eq. cap $^{-1} \mathrm{yr}^{-1}$ from the STU). A life cycle assessment of nearly 800 septic tank systems without soil dispersal in Poland showed that approximately $27 \%$ of total cradle-to-grave GHG emissions (i.e. $5.21 \mathrm{kgCO}_{2}$ eq. $\mathrm{cap}^{-1} \mathrm{yr}^{-1}$ ) were released during the operational phase of the system, of which about half was attributed to direct GHG emissions to the atmosphere (Burchart-Korol et al., 2019). Whilst it is difficult to generalise about GHG emissions associated with centralised wastewater treatment systems used to serve urban populations given the different number of permutations (and studies) on GHG emissions from different process combinations and size of plants, the Ecoinvent database used for Life Cycle Analysis Ecoinvent (2021) returns similar GHG emissions of 346 and $349 \mathrm{~kg}-\mathrm{CO}_{2}$ eq. $\mathrm{cap}^{-1} \mathrm{yr}^{-1}$ for population equivalents of approximately 3000 and 200000 , respectively, which provide an interesting comparison to the on-site wastewater treatment systems.

Finally, this study provides data that can be used to refine emission factors used for on-site wastewater treatment in terms of IPCC national accounting for $\mathrm{CH}_{4}$ and $\mathrm{N}_{2} \mathrm{O}$ emissions (note, $\mathrm{CO}_{2}$ emissions are not counted in such accounting as these are considered to be of biogenic origin). In the recent 2019 refinement to the 2006 IPCC Guidelines for National Greenhouse Gas Inventories, on-site systems are considered under the uncollected wastewater category and have been broken down into septic tank systems with and without dispersion fields (i.e. STUs); there are no further categories of different permutations of on-site system design, as have been evaluated in this study. The IPCC emission factors for septic tank systems with dispersion fields are stated at $0.125 \mathrm{~kg}_{-} \mathrm{CH}_{4}(\mathrm{~kg}-\mathrm{COD})^{-1}$ and $0.0045 \mathrm{~kg}-\mathrm{N}_{2} \mathrm{O}-\mathrm{N}(\mathrm{kg}-\mathrm{N})^{-1}$, which can be compared against the mean emission factors from this research as $0.0036 \mathrm{~kg}-\mathrm{CH}_{4}(\mathrm{~kg}-\mathrm{COD})^{-1}$ and $0.0003 \mathrm{~kg}-\mathrm{N}_{2} \mathrm{O}-\mathrm{N}(\mathrm{kg} \mathrm{N})^{-1}$, respectively, an order of magnitude lower. This would therefore suggest that the IPCC guidelines are significantly over-estimating GHG emissions associated with on-site wastewater treatment at present. The guidelines do presume that all $\mathrm{CH}_{4}$ emissions are produced within the septic tank (with negligible emission from the STU), whilst $\mathrm{N}_{2} \mathrm{O}$ emissions are produced in the effluent dispersal system in the soil, which would seem to be corroborated by this study. Using improved emission factors based on recent studies, a survey of the global impact of decentralised sanitation technologies (Shaw et al., 2021) found that septic tank systems were amongst the main contributors of sanitation-related GHG emissions in all scenarios that would allow the achievement of Sustainable Development Goal (SDG) 6.2 (i.e. ending open defecation by 2030). Although total sanitation-related emissions are expected to increase, they are comparatively very small $(0.2 \%$ of total global anthropogenic $\mathrm{CO}_{2}$ emissions) and offer affordable and scalable forms of sanitation which yield the potential for energy capture and reuse (i.e. lower emission potential) in the form of $\mathrm{CH}_{4}$ capture directly at the source.

\subsection{Minimum dataset requirement to gain accurate flux estimates}

Finally, an attempt has been made to determine a minimum dataset (spatially and temporally) required using the more commonly available discrete measurement methodology which might approximate the accuracy of flux estimates made using continuous measurements. Overall, observed soil GHG fluxes showed clear diurnal and seasonal patterns and were correlated to environmental parameters such as temperature and moisture status in the soil. Continuous measurements appeared to provide a more accurate representation of the full variability of fluxes as survey measurements are usually limited to daytime hours. In practice it might, however, not always be possible to deploy long-term continuous measurements in the field. A linear mixed effects (LMEs) model similar to Truhlar et al. (2019) for $\mathrm{CO}_{2}$ and $\mathrm{CH}_{4}$ fluxes was used to estimate the effect of different spatially distributed discrete sampling techniques on regression coefficients. The LME model included site (Site A, Site B) and location (PE, $\mathrm{SE}$, Control) as random effects and the four highest correlated environmental factors (soil and air temperature, VWC, 
SMD) as fixed effects. As the limiting factor for discrete sampling will most likely be manual work by field personnel, we focused on two realistic sampling strategies: (i) fewer measurements per day but measurement over several consecutive days (i.e. one morning and one evening measurement per day on each weekday) and (ii) more measurements on a single day but fewer overall sampling days (i.e. eight daytime measurements per day in $2 \mathrm{~h}$ intervals during daytime hours on one day per week). Comparing the distribution of modelled parameter estimates (Fig. S5 in the Supplement) with the outcomes from models using the full dataset from continuous and discrete measurements, we conclude that while neither discrete approach can replicate the results obtained from the continuous measurements, the approach of sampling more frequently during the day on fewer overall days provided regression coefficient point estimates closer to those of the full dataset (i.e. higher accuracy) compared to sparser sampling on consecutive days. Resulting coefficient estimate distributions however were comparatively wide (i.e. low accuracy) for both $\mathrm{CO}_{2}$ and $\mathrm{CH}_{4}$, but generally better for $\mathrm{CO}_{2}$. As shown in this and other studies, microbially induced gas fluxes are generally driven by $\mathrm{C}$ availability in the soil, environmental factors and soil characteristics. It is important to sample over a preferably wide range of temperature and moisture conditions to optimally capture natural and systemspecific gas flux variations.

\section{Conclusions}

This study provides the first field-scale comparison of the effect of different levels pre-treatment on greenhouse gas emissions from on-site wastewater treatment systems across a year. This research demonstrates that GHG emissions from the different parts of the DWWTSs are highly variable and correlated to environmental factors and water usage patterns. The highest measured $\mathrm{CO}_{2}$ flux rates were observed from the STUs at both sites; however, when these rates were adjusted to account for the background soil emissions, one STU was a relatively high net emitter of $\mathrm{CO}_{2}$ emissions compared to the other STU, which was apparently emitting less $\mathrm{CO}_{2}$ emissions in comparison to the background soil. However, both sites were also characterised by high emissions from their vent systems for the percolation pipes, implying that much of the gases generated by microbial soil treatment processes on the percolating effluent were escaping via the vent system compared to the soil. Vent fluxes were characterised by a low number of high-emission events, which were responsible for the majority of total observed vent emissions, indicating that improved measurement techniques would be needed to accurately assess vent emissions in the future. The STs contributed to the highest $\mathrm{CH}_{4}$ emissions at both sites, as found in other similar recent studies (e.g. Diaz-Valbuena et al., 2011), and the highest $\mathrm{N}_{2} \mathrm{O}$ fluxes were measured in the vent systems at both sites.
The total net GHG emissions from a conventional septic tank system with STU based on the results from both sites is $9.99 \mathrm{~kg}-\mathrm{CO}_{2}$ eq. $\mathrm{yr}^{-1} \mathrm{cap}^{-1}$. Approximately $63 \%$ of the total net emissions were in the form of $\mathrm{CO}_{2}$, around $27 \%$ were $\mathrm{CH}_{4}$ and less than $10 \%$ were $\mathrm{N}_{2} \mathrm{O}$. Comparing a hypothetical on-site treatment system with and without packaged secondary module equated to an additional $9.44 \mathrm{~kg}-\mathrm{CO}_{2}$ eq. cap ${ }^{-1} \mathrm{yr}^{-1}$ of emissions from the STU system if it receives PE directly compared to SE from the secondary treatment module, with much of that difference probably emitted by the secondary treatment package system. This study therefore has provided insights into implications for managing GHG emissions from DWWTSs that can be attained by different system configurations as well as providing data that suggest that the current IPCC emission factors for $\mathrm{CH}_{4}$ and $\mathrm{N}_{2} \mathrm{O}$ are significantly overestimating emissions for standard on-site wastewater treatment systems comprising of a septic tank and soil treatment area.

Data availability. The datasets that this research has been based on can be found in Knappe et al. (2022, https://doi.org/10.17632/ s6jmnhmyzf.1).

Supplement. The supplement related to this article is available online at: https://doi.org/10.5194/bg-19-1067-2022-supplement.

Author contributions. LWG conceived the study and gained the required funding. LWG, JK and CS planned the experiments. JK and CS performed the experiments and analysed data. All authors interpreted the results, wrote and reviewed the paper.

Competing interests. The contact author has declared that neither they nor their co-authors have any competing interests.

Disclaimer. Publisher's note: Copernicus Publications remains neutral with regard to jurisdictional claims in published maps and institutional affiliations.

Acknowledgements. This work was supported by the Science Foundation Ireland under grant number 13/IA/1923. The authors thank the house owners for enabling continued access to the research sites, as well as Patrick Veale for assistance with fieldwork.

Financial support. This research has been supported by the Science Foundation Ireland (grant no. 13/IA/1923).

Review statement. This paper was edited by Tina Treude and reviewed by two anonymous referees. 


\section{References}

Allen, R. G., Pereira, L. S., Raes, D., and Smith, M.: Crop evapotranspiration - guidelines for computing crop water requirements, Food and Agriculture Organization, Rome, Italy, 1998.

Ambus, P. and Christensen, S.: Spatial and seasonal nitrous oxide and methane fluxes in Danish forest-, grassland-, and agroecosystems, J. Environ Qual., 24, 993-1001, https://doi.org/10.2134/jeq1995.00472425002400050031x, 1995.

Anderson, F. L., Cooper, J. A., and Amador, J. A.: Laboratoryscale evaluation of the effects of water-filled pore space on emissions of $\mathrm{CO}_{2}, \mathrm{CH}_{4}, \mathrm{~N}_{2} \mathrm{O}$, and $\mathrm{N}_{2}$ from soilbased wastewater treatment, Water Air Soil Poll., 230, 245, https://doi.org/10.1007/s11270-019-4294-7, 2019.

Banjanovic, E. S. and Osborne, J. W.: Confidence intervals for effect sizes: applying bootstrap resampling, Prac. Assess. Res. Eval., 21, 5, https://doi.org/10.7275/dz3r-8n08, 2016.

Bastviken, D., Tranvik, L. J., Downing, J. A., Crill, P. M., and Enrich-Prast, A.: Freshwater methane emissions offset the continental carbon sink, Science, 331, 50, https://doi.org/10.1126/science.1196808, 2011.

Beach, D. N. H., McCray, J. E., Lowe, K. S., and Siegrist, R. L.: Temporal changes in hydraulic conductivity of sand porous media biofilters during wastewater infiltration due to biomat formation, J. Hydrol., 311, 230-243, https://doi.org/10.1016/j.jhydrol.2005.01.024, 2005.

Beal, C. D., Gardner, E. A., and Menzies, N. W.: Process, performance, and pollution potential: A review of septic tank - soil absorption systems, Aust. J. Soil Res., 43, 781, https://doi.org/10.1071/SR05018, 2005.

Blackett, I., Hawkins, P. M., and Heymans, C.: The Missing Link in Sanitation Service Delivery: A Review of Fecal Sludge Management in 12 Cities, World Bank Global Water Practice - Water and Sanitation Program (WSP), https://www.wsp.org/sites/wsp/files/publications/ WSP-Fecal-Sludge-12-City-Review-Research-Brief.pdf (last access: 9 February 2022) 2014.

Bogner, J., Pipatti, R., Hashimoto, S., Diaz, C., Mareckova, K., Diaz, L., Kjeldsen, P., Monni, S., Faaij, A., Gao, Q., Zhang, T., Ahmed, M. A., Sutamuhardja, R. T. M., and Gregory, R.: Mitigation of global greenhouse gas emissions from waste: conclusions and strategies from the Intergovernmental Panel on Climate Change (IPCC) Fourth Assessment Report. Working Group III (Mitigation), Waste Manage. Res., 26, 11-32, https://doi.org/10.1177/0734242X07088433, 2008.

Bouma, J.: Unsaturated flow during soil treatment of septic tank effluent, J. Env. Eng. Div.-ASCE, 101, 967-983, https://doi.org/10.1061/JEEGAV.0000438, 1975.

Braun, M., Bai, Y., McConkey, B., Farrell, R., Romo, J., and Pennock, D.: Greenhouse gas flux in a temperate grassland as affected by landform and disturbance, Landscape Ecol., 28, 709723, https://doi.org/10.1007/s10980-013-9878-9, 2013.

Burchart-Korol, D. and Zawartka, P.: Environmental life cycle assessment of septic tanks in urban wastewater system a case study for Poland, Arch. Environ. Prot., 45, 68-77, https://doi.org/10.24425/aep.2019.130243, 2019.

Cakir, F. Y. and Stenstrom, M. K.: Greenhouse gas production: a comparison between aerobic and anaerobic wastew- ater treatment technology, Water Res., 39, 4197-4203, https://doi.org/10.1016/j.watres.2005.07.042, 2005.

Carpenter J. and Bithell J.: Bootstrap confidence intervals: when, which, what? A practical guide for medical statisticians, Stat. Med., 19, 1141-1164, https://doi.org/10.1002/(SICI)10970258(20000515)19:9<1141:AID-SIM479>3.0.CO;2-F, 2000.

Cooper, J. A., Loomis, G. W., and Amador, J. A.: Hell and high water: diminished septic system performance in coastal regions due to climate change, Plos One, 11, e0162104, https://doi.org/10.1371/journal.pone.0162104, 2016.

Czepiel, P. M., Crill, P. M., and Harriss, R. C.: Methane emissions from municipal wastewater treatment processes, Environ. Sci. Technol., 27, 2472-2477, https://doi.org/10.1021/es00048a025, 1993.

Diaz-Valbuena, L. R., Leverenz, H. L., Cappa, C. D., Tchobanoglous, G., Horwath, W. R., and Darby, J. L.: Methane, carbon dioxide, and nitrous oxide emissions from septic tank systems, Environ. Sci. Technol., 45, 2741-2747, https://doi.org/10.1021/es1036095, 2011.

Dubber D., Knappe J., and Gill L. W.: Characterisation of organic matter and its transformation processes in on-site wastewater effluent percolating through soil using fluorescence spectroscopic methods and parallel factor analysis (PARAFAC), Water, 13, 2627, https://doi.org/10.3390/w13192627, 2021.

Dunfield, P. F., Topp, E., Archambault, C., and Knowles, R.: Effect of nitrogen fertilizers and moisture content on $\mathrm{CH}_{4}$ and $\mathrm{N}_{2} \mathrm{O}$ fluxes in a humisol: measurements in the field and intact soil cores, Biogeochemistry, 29, 199-222, https://doi.org/10.1007/BF02186048, 1995.

Ecoinvent: Ecoinvent v3.6, https://www.ecoinvent.org/, last access: 3 December 2021.

EEA: Eurostat database, European Environment Agency, http://www.eea.europa.eu/publications/ environmental-pressures-from-european-consumption (last access: 9 January 2021), 2013.

EPA: Ireland's national inventory submissions 2018, Environmental Protection Agency, Johnstown Castle, Co. Wexford, Ireland, 2018.

Fernández-Baca, C. P., Truhlar, A. M., Omar, A.-E. H., Rahm, B. G., Walter, M. T., and Richardson, R. E.: Methane and nitrous oxide cycling microbial communities in soils above septic leach fields: Abundances with depth and correlations with net surface emissions, Sci. Total Environ., 640-641, 429-441, https://doi.org/10.1016/j.scitotenv.2018.05.303, 2018.

Fernández-Baca, C. P., Truhlar, A. M., Omar, A.-E, Reid, M. C., and Richardson, R. E.: Temporal lags in postrain greenhouse gas cycling and fluxes from septic leach field soils and associated greenhouse gas cycling microbial populations, J. Sust. Water Built Env., 6, 04020004, https://doi.org/10.1061/JSWBAY.0000910, 2020.

Gill, L. W., O'Luanaigh, N., Johnston, P. M., Misstear, B. D. R., and O'Suilleabhain, C.: Nutrient loading on subsoils from on-site wastewater effluent, comparing septic tank and secondary treatment systems, Water Res., 43, 2739-2749, https://doi.org/10.1016/j.watres.2009.03.024, 2009.

Gill, L. W., Mac Mahon, J., Knappe, J., Gharbia, S., and Pilla, F.: Desludging rates and mechanisms for domestic wastewater treatment system sludges in Ireland, STRIVE Report Series No. 253, 
Environmental Protection Agency, Wexford, Ireland, ISBN 9781-84095-782-2, 2018.

Hope, D., Dawson, J. J. C., Cresser, M. S., and Billett, M. F.: A method for measuring free $\mathrm{CO}_{2}$ in upland stream water using headspace analysis, J. Hydrol., 166, 1-14, https://doi.org/10.1016/0022-1694(94)02628-O, 1995.

Hu, H.-Y., Cheng, Y.-L., and Lin, J.-Y.: On-Site Treatment of Septic Tank Effluent by Using a Soil Adsorption System, Practice Periodical of Hazardous, Toxic, and Radioactive Waste Management, 11, 197-206, https://doi.org/10.1061/(ASCE)1090025X(2007)11:3(197), 2007.

Huynh, L. T., Harada, H., Fujii, S., Nguyen, L. P. H., Hoang, T.H. T., and Huynh, H. T.: Greenhouse gas emissions from blackwater septic systems, Environ. Sci. Technol., 55, 1209-1217, https://doi.org/10.1021/acs.est.0c03418, 2021.

IPCC: Climate Change 2013: The Physical Science Basis. Contribution of Working Group I to the Fifth Assessment Report of the Intergovernmental Panel on Climate Change, Cambridge University Press, Cambridge, UK and New York, NY, USA, 2013.

Johansson, A. E., Gustavsson, A. M., Oquist, M. G., and Svensson, B. H.: Methane emissions from a constructed wetland treating wastewater-seasonal and spatial distribution and dependence on edaphic factors, Water Res., 38, 3960-3970, https://doi.org/10.1016/j.watres.2004.07.008, 2004.

Jones, J. and Taylor, G.: Septic tank effluent percolation through sands under laboratory conditions, Soil Sci., 99, 301-309, 1965.

Knappe, J., Somlai, C., Fowler, A. C., and Gill, L. W.: The influence of pre-treatment on biomat development in soil treatment units, J. Contam. Hydrol., 232, 103654, https://doi.org/10.1016/j.jconhyd.2020.103654, 2020.

Knappe, J., Somlai, C., and Gill, L.: Data for: Assessing the spatial and temporal variability of GHG emissions from different configurations of on-site wastewater treatment system using discrete and continuous gas flux measurement, V1, Mendeley Data [data set], https://doi.org/10.17632/s6jmnhmyzf.1, 2022.

Leverenz, H. L., Tchobanoglous, G., and Darby, J. L.: Evaluation of Greenhouse Gas Emissions from Septic Systems, Water Intelligence Online, 10, 9781780403359, https://doi.org/10.2166/9781780403359, 2011.

Le Mer, J. and Roger, P.: Production, oxidation, emission and consumption of methane by soils: A review, Eur. J. Soil Biol., 37, 25-50, https://doi.org/10.1016/S1164-5563(01)01067-6, 2001.

Mac Mahon J., Knappe J., and Gill L. W.: Sludge accumulation rates in septic tanks used as part of the on-site treatment of domestic wastewater systems in a northern maritime temperate climate, J. Environ. Manage., 304, 114199, https://doi.org/10.1016/j.jenvman.2021.114199, 2022.

Masuda, S., Suzuki, S., Sano, I., Li, Y.-Y., and Nishimura, O.: The seasonal variation of emission of greenhouse gases from a full-scale sewage treatment plant, Chemosphere, 140, 167-173, https://doi.org/10.1016/j.chemosphere.2014.09.042, 2015.

McKinley, J. W. and Siegrist, R. L.: Accumulation of organic matter components in soil under conditions imposed by wastewater infiltration, Soil Sci. Soc. Am. J., 74, 1690, https://doi.org/10.2136/sssaj2009.0395, 2010.

Mosier, A., Schimel, D., Valentine, D., Bronson, K., and Parton, W.: Methane and nitrous oxide fluxes in native, fertilized and cultivated grasslands, Nature, 350, 330, https://doi.org/10.1038/350330a0, 1991.
Mosier, A., Parton, W., Valentine, D., Ojima, D., Schimel, D., and Heinemeyer, O.: $\mathrm{CH}_{4}$ and $\mathrm{N}_{2} \mathrm{O}$ fluxes in the Colorado shortgrass steppe: 2. Long-term impact of land use change, Global Biogeochem. Cy., 11, 29-42, https://doi.org/10.1029/96GB03612, 1997.

Natchimuthu, S.: Freshwater methane and carbon dioxide uxes: Spatio-temporal variability and an integrated assessment of lake and stream emissions in a catchment, 673, https://doi.org/10.3384/diss.diva.126779, Linkoping University Electronic Press, 2016.

R Core Team: R: A language and environment for statistical computing, R Foundation for Statistical Computing, Vienna, Austria, 2019.

Schulte, R. P., Diamond, J., Finkele, K., Holden, N. M., and Brereton, A. J.: Predicting the soil moisture conditions of Irish grasslands, Irish J. Agr. Food Res., 44, 95-110, 2005.

Shahidian, S., Serralheiro, R., Serrano, J., Teixeira, J., Haie, N., and Santos, F.: Hargreaves and Other Reduced-Set Methods for Calculating Evapotranspiration, in: Evapotranspiration - Remote Sensing and Modeling, edited by: Irmak, A., InTech., 2012.

Shaw, K., Kennedy, C., and Dorea, C. C.: Non-Sewered Sanitation Systems' Global Greenhouse Gas Emissions: Balancing Sustainable Development Goal Tradeoffs to End Open Defecation, Sustainability, 13, 11884, https://doi.org/10.3390/su132111884, 2021.

Siegrist, R. L. and Boyle, W. C.: Wastewater-induced soil clogging development, J. Env. Eng., 113, 550-566, https://doi.org/10.1061/(ASCE)0733-9372(1987)113:3(550), 1987.

Smith, K. A., McTaggart, I. P., Dobbie, K. E., and Conen, F.: Emissions of $\mathrm{N}_{2} \mathrm{O}$ from Scottish agricultural soils as a function of fertiliser N, Nutr. Cycl. Agroecosys., 52, 123-130, https://doi.org/10.1023/A:1009781518738, 1998.

Smith, K. A., Ball, T., Conen, F., Dobbie, K. E., Massheder, J., and Rey, R.: Exchange of greenhouse gases between soil and atmosphere: interactions of soil physical factors and biological processes, Eur. J. Soil Sci., 54, 779-791, https://doi.org/10.1046/J.1351-0754.2003.0567.X, 2003.

Somlai, C., Knappe, J., and Gill, L. W.: Spatial and temporal variation of $\mathrm{CO}_{2}$ and $\mathrm{CH}_{4}$ emissions from a septic tank soakaway, Sci. Total Environ., 679, 185-195, https://doi.org/10.1016/j.scitotenv.2019.04.449, 2019.

Somlai-Haase, C., Knappe, J., and Gill, L.: Carbon dioxide emissions from a septic tank soakaway in a northern maritime climate, Sci. Total Environ., 586, 485-491, https://doi.org/10.1016/j.scitotenv.2017.01.206, 2017.

Sullivan, G. M. and Feinn, R.: Using Effect Size-or Why the $P$ Value Is Not Enough, Journal of Graduate Medical Education, 4, 279-82, https://doi.org/10.4300/JGME-D-12-00156.1, 2012.

Swenson, M. M., Regan, S., Bremmers, D. T. H., Lawless, J., Saunders, M., and Gill, L. W.: Carbon balance of a restored and cutover raised bog: implications for restoration and comparison to global trends, Biogeosciences, 16, 713-731, https://doi.org/10.5194/bg-16-713-2019, 2019.

Thomas, R. E., Schwartz, W. A., and Bendixen, T. W. Soil chemical changes and infiltration rate reduction under sewage spreading1, Soil Sci. Soc. Am. J., 30, 641, https://doi.org/10.2136/sssaj1966.03615995003000050030x, 1966. 
Tomaras, J., Sahl, J. W., Siegrist, R. L., and Spear, J. R.: Microbial diversity of septic tank effluent and a soil biomat, Appl. Environ. Microb., 75, 3348-3351, https://doi.org/10.1128/AEM.0056008, 2009.

Truhlar, A. M., Rahm, B. G., Brooks, R. A., Nadeau, S. A., Makarsky, E. T., and Walter, M. T.: Greenhouse gas emissions from septic systems in New York State, J. Environ. Qual., 45, 1153-1160, https://doi.org/10.2134/jeq2015.09.0478, 2016.

Truhlar, A. M., Ortega, K. L., and Walter M. T.: Seasonal and diel variation in greenhouse gas emissions from septic system leach fields, Int. J. Environ. Sci. Te., 16, 6043-6052, https://doi.org/10.1007/s13762-019-02314-6, 2019.

US EPA: Global Non-CO 2 GHG Emissions: 1990-2030, U.S. Environmental Protection Agency, Washington, DC, USA, 2012.

US EPA: Inventory of U.S. greenhouse gas emissions and sinks: 1990-2014, U.S. Environmental Protection Agency, Washington, DC, USA, 2016.

Van Cuyk, S., Siegrist, R., Logan, A., Masson, S., Fischer, E., and Figueroa, L.: Hydraulic and purification behaviors and their interactions during wastewater treatment in soil infiltration systems, Water Res., 35, 953-964, https://doi.org/10.1016/S00431354(00)00349-3, 2001.
Wigginton, S. K., Loomis, G. W., and Amador, J. A.: Greenhouse gas emissions from lignocellulose-amended soil treatment areas for removal of nitrogen from wastewater, Sci. Total Environ., 744, 140936, https://doi.org/10.1016/j.scitotenv.2020.140936, 2020.

Wilhelm, S. R., Schiff, S. L., and Cherry, J. A.: Biogeochemical evolution of domestic waste water in septic systems: 1. Conceptual model, Ground Water, 32, 905-916, https://doi.org/10.1111/j.1745-6584.1994.tb00930.x, 1994.

Yoshida, H., Mønster, J., and Scheutz, C.: Plant-integrated measurement of greenhouse gas emissions from a municipal wastewater treatment plant, Water Res., 61, 108-118, https://doi.org/10.1016/j.watres.2014.05.014, 2014.

Yver Kwok, C. E., Müller, D., Caldow, C., Lebègue, B., Mønster, J. G., Rella, C. W., Scheutz, C., Schmidt, M., Ramonet, M., Warneke, T., Broquet, G., and Ciais, P.: Methane emission estimates using chamber and tracer release experiments for a municipal waste water treatment plant, Atmos. Meas. Tech., 8, 2853 2867, https://doi.org/10.5194/amt-8-2853-2015, 2015. 